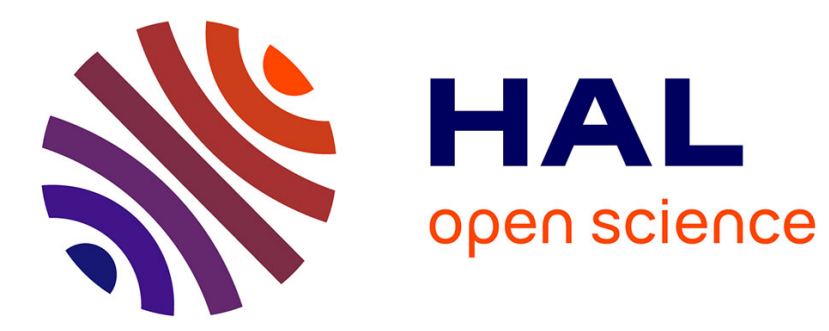

\title{
Oxidation of 316L(N) Stainless Steel in Liquid Sodium at $650{ }^{\circ} \mathrm{C}$
}

\author{
Matthieu Rivollier, J. L. Courouau, Michel Tabarant, Cécile Blanc, \\ Marie-Laurence Giorgi
}

\section{> To cite this version:}

Matthieu Rivollier, J. L. Courouau, Michel Tabarant, Cécile Blanc, Marie-Laurence Giorgi. Oxidation of $316 \mathrm{~L}(\mathrm{~N})$ Stainless Steel in Liquid Sodium at $650{ }^{\circ} \mathrm{C}$. Journal of Nuclear Materials, 2018, 500, pp.337 - 348. 10.1016/j.jnucmat.2017.12.037 . hal-01810057

\section{HAL Id: hal-01810057 \\ https://hal-centralesupelec.archives-ouvertes.fr/hal-01810057}

Submitted on 7 Jun 2018

HAL is a multi-disciplinary open access archive for the deposit and dissemination of scientific research documents, whether they are published or not. The documents may come from teaching and research institutions in France or abroad, or from public or private research centers.
L'archive ouverte pluridisciplinaire HAL, est destinée au dépôt et à la diffusion de documents scientifiques de niveau recherche, publiés ou non, émanant des établissements d'enseignement et de recherche français ou étrangers, des laboratoires publics ou privés. 


\section{Accepted Manuscript}

Oxidation of $316 \mathrm{~L}(\mathrm{~N})$ stainless steel in liquid sodium at $650 \square^{\circ} \mathrm{C}$

Matthieu Rivollier, Jean-Louis Courouau, Michel Tabarant, Cécile Blanc, MarieLaurence Giorgi

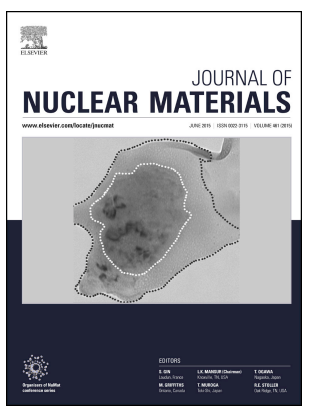

PII:

S0022-3115(17)31275-8

DOI:

10.1016/j.jnucmat.2017.12.037

Reference: NUMA 50702

To appear in: Journal of Nuclear Materials

Received Date: 19 September 2017

Revised Date: 5 December 2017

Accepted Date: 24 December 2017

Please cite this article as: M. Rivollier, J.-L. Courouau, M. Tabarant, Cé. Blanc, M.-L. Giorgi, Oxidation of $316 \mathrm{~L}(\mathrm{~N})$ stainless steel in liquid sodium at $650 \square^{\circ} \mathrm{C}$,ournal of Nuclear Materials (2018), doi: 10.1016/ j.jnucmat.2017.12.037.

This is a PDF file of an unedited manuscript that has been accepted for publication. As a service to our customers we are providing this early version of the manuscript. The manuscript will undergo copyediting, typesetting, and review of the resulting proof before it is published in its final form. Please note that during the production process errors may be discovered which could affect the content, and all legal disclaimers that apply to the journal pertain. 


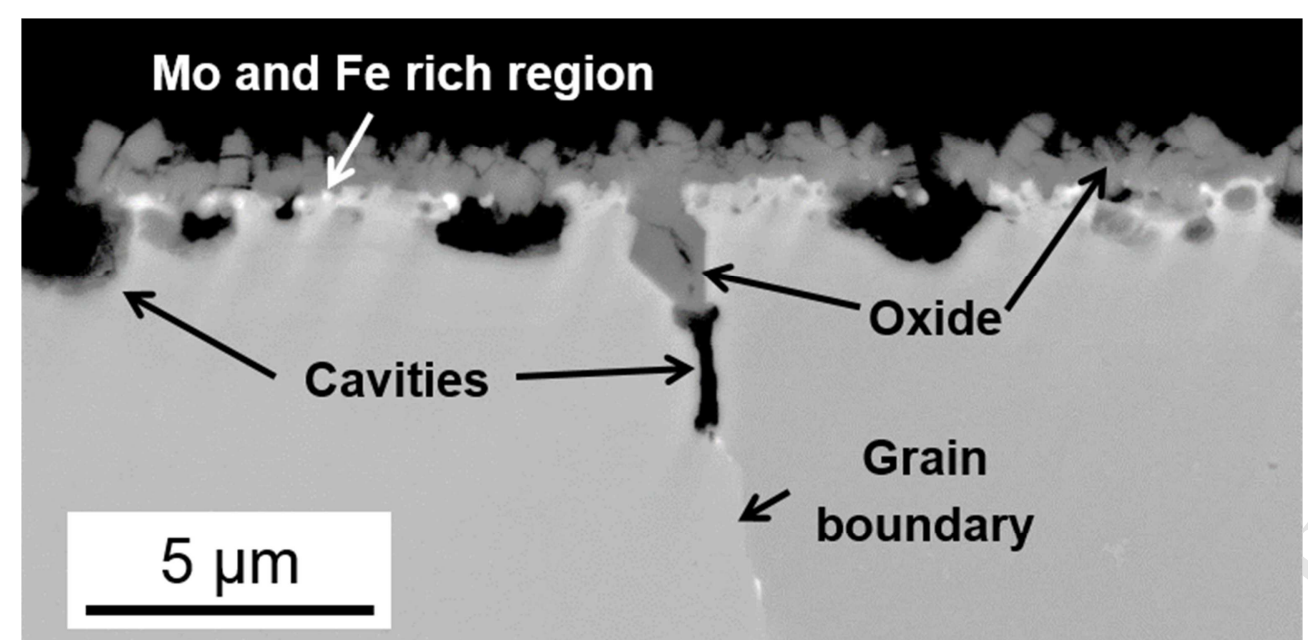




\section{Matthieu Rivollier, ${ }^{1,2}$, Jean-Louis Courouau, ${ }^{1, *}$, Michel}

\section{Tabarant $^{3}$, Cécile Blanc ${ }^{3}$, Marie-Laurence Giorgi ${ }^{2}$}

${ }^{1}$ Den-Service de la Corrosion et du Comportement des Matériaux dans leur Environnement (SCCME), CEA, Université Paris-Saclay, F-91191, Gif-sur-Yvette, France

${ }^{2}$ CentraleSupélec, Université Paris-Saclay, Laboratoire de Génie des Procédés et Matériaux, 3 rue Joliot-Curie, F-91192 Gif-sur-Yvette cedex, France

${ }^{3}$ Den-Service d'Études Analytiques et de Réactivité des Surfaces (SEARS), CEA, Université Paris-Saclay, F-91191, Gif-sur-Yvette, France

11 matthieu.rivollier@centralesupelec.fr; jean-louis.courouau@cea.fr; michel.tabarant@cea.fr; cecile.blanc@cea.fr; marie-laurence.giorgi@centralesupelec.fr 
15 Abstract

16 The corrosion of an austenitic steel in liquid sodium containing $189 \mu \mathrm{g} \cdot \mathrm{g}^{-1}$ of oxygen was

17 investigated at $650^{\circ} \mathrm{C}$ as a function of time $(122,250$ and $500 \mathrm{~h})$. The steel samples were

18 characterized by means of complementary techniques, namely scanning electron microscopy, X-

19 ray diffraction, glow discharge optical emission spectroscopy and transmission electron

20 microscopy. The characterizations showed that a $\mathrm{NaCrO}_{2}$ oxide scale forms at the steel surface.

21 Under this oxide scale, iron and molybdenum rich $\mathrm{M}_{6} \mathrm{C}$ carbide particles together with $\mathrm{NaCrO}_{2}$ in

22 the grain boundaries and cavities filled with sodium were observed. The stainless steel substrate

23 and / or the chromite scale were dissolved in parallel with the formation of chromite and carbides.

24 Thermodynamic calculations showed that $\mathrm{NaCrO}_{2}$ and $\mathrm{M}_{6} \mathrm{C}$ are equilibrium phases in such a

25 system. $\mathrm{NaCrO}_{2}$ is formed by the reaction of chromium diffusing from the steel bulk with sodium

26 and dissolved oxygen (external selective oxidation). Mo segregates to the steel surface where it

27 reacts with $\mathrm{Fe}$ from the steel and $\mathrm{C}$ dissolved in liquid sodium. The dissolution of stainless steel

28 occurred since the liquid sodium bath is not saturated in the dissolving species (pure metals and

29 oxides such as $\mathrm{NaCrO}_{2}, \mathrm{Na}_{4} \mathrm{FeO}_{3}$ ). As for the cavities, vacancies are created at the steel $/ \mathrm{NaCrO}_{2}$

30 interface by Cr oxidation, carburization and dissolution of the other elements present in the

31 stainless steel. The vacancies become supersaturated and this leads to the nucleation of the

32 cavities observed. Part of the vacancies created by Cr oxidation or steel dissolution is annihilated

33 at sinks like dislocations leading to the translation of the oxide / metal interface towards the metal

34 bulk.

35 Keywords: liquid sodium, austenitic steel, high temperature corrosion, selective oxidation 


\section{Introduction}

38 France made plans to construct the fourth generation of nuclear reactor and chose the Sodium-

39 Cooled Fast Reactor (SFR) as the technology to develop. The expected economically reasonable

40 service life-time of a reactor is 60 years. In these reactors, liquid sodium $\mathrm{Na}$ is used as a coolant

41 at high temperatures $\left(400\right.$ to $550^{\circ} \mathrm{C}$ for the liquid metal bulk and up to $650^{\circ} \mathrm{C}$ at the hot spots of

42 the fuel claddings) [1]. As the chemical conditions can change with time (normal, transient and

43 incidental), any interactions between the liquid metal and the structural materials (made mainly

44 of austenitic steels) must be well known, well understood and predicted to guarantee service life-

45 time as well as resistance to incidental conditions.

46 In sodium-cooled fast reactors, the liquid metal oxygen content is maintained at a maximum of

$47 \quad 10 \mu \mathrm{g} \cdot \mathrm{g}^{-1}$ by means of purification systems, in order to prevent solid oxide from precipitating in

48 the circulation loops and minimize corrosion of the structural materials. However, certain events

49 such as air or water leaks could occur during the service life-time of the nuclear reactor, leading

50 to a temporary increase in the dissolved oxygen content $\left(15 \mu \mathrm{g} . \mathrm{g}^{-1}\right.$ to $200 \mu \mathrm{g}^{\mathrm{g}} \mathrm{g}^{-1}$ for unexpected

51 transient) [2].

52 For austenitic steels immersed in liquid sodium containing low oxygen levels (less than $10 \mu \mathrm{g} . \mathrm{g}^{-}$

$53^{1}$ ) for a few hundred or thousand hours, the corrosion is mainly due to the preferential dissolution

54 of nickel and, to a lesser extent, chromium and manganese. This preferential dissolution leads to

55 the ferritization of the steel surface. The thickness of the ferrite layer formed is of the order of a

56 few $\mu \mathrm{m}$ [3-8]. At longer immersion times, austenitic steels are dissolved homogeneously with a

57 kinetic attributed to iron dissolution $[3,4]$. An increase in the oxygen content or in the

58 temperature is reported to increase the dissolution rate $[4,6,7,9]$. This is explained by an increase 
59 of the iron solubility in sodium in presence of oxygen [10,11]. Kolster et al. [12] show that

60 oxygen might also increase the preferential dissolution rate of chromium, due to the formation of

61 a Na-Cr-O dissolved complex.

62 At higher oxygen contents in liquid sodium, i.e. more than $15 \mu \mathrm{g} \cdot \mathrm{g}^{-1}[8,13]$, oxide scales rich in

$63 \mathrm{Na}$ and $\mathrm{Cr}$ are formed on the surface of austenitic or ferritic / martensitic steels. This oxide is

$64 \mathrm{Na}_{2} \mathrm{O} \cdot \mathrm{Cr}_{2} \mathrm{O}_{3}$, also called sodium chromite $\mathrm{NaCrO}_{2}$ [8,9,14-16]. An increase in the oxygen content

65 or in the temperature is reported to increase the oxidation rate [13-15]. The $\mathrm{NaCrO}_{2}$ formation

66 causes $\mathrm{Cr}$ depletion in the steel under the oxide scale, for both ferritic / martensitic [15,17] and

67 austenitic steels [15]. In this case, the steel grain boundaries can be enriched in $\mathrm{Na}$ and $\mathrm{O}$ [14].

68 A discontinuous phase rich in Mo can also be formed at the surface or subsurface of steels

69 containing Mo immersed in liquid sodium [3]. This phase could be $\mathrm{Fe}_{7} \mathrm{Mo}_{6}$ or $\mathrm{M}_{6} \mathrm{C}$ type carbides

70 at temperatures higher than $650^{\circ} \mathrm{C}, \mathrm{M}$ being $\mathrm{Cr}, \mathrm{Mn}, \mathrm{Fe}, \mathrm{Ni}$ or Mo (liquid sodium contains traces

71 of C) [8]. For instance, $\mathrm{Fe}_{4} \mathrm{Mo}_{2} \mathrm{C}$ was detected as shown in ref. [9].

72 Finally, it can be concluded from this literature review that the mechanisms involved in the

73 corrosion of austenitic steels in liquid sodium are very complex and not yet fully understood [18].

74 In recent years, as the experiments using liquid $\mathrm{Na}$ are not easy to perform, there are few studies

75 on the corrosion in liquid $\mathrm{Na}$. The influence of immersion time and dissolved oxygen content is

76 not studied precisely enough to be confident in the results that could be obtained at long

77 immersion times. The primary goal of our study, therefore, is to gain a better understanding of the

78 corrosion mechanisms involved in liquid sodium in controlled temperature and oxygen content

79 conditions and to investigate further a key step in the corrosion process: $\mathrm{Cr}$ diffusion from the

80 steel bulk to the steel surface. The work is divided into the following stages: 
81 1) Immersion of the chosen austenitic steel in liquid $\mathrm{Na}$ containing $189 \mu \mathrm{g} \cdot \mathrm{g}^{-1}$ of oxygen at $650^{\circ} \mathrm{C}$

82 for different immersion times up to $500 \mathrm{~h}$;

83 2) Characterization of the samples obtained to determine the nature and composition of the

84 corrosion products and estimate the oxidation depth;

85 3) Measurement of chromium concentration profiles in the vicinity of grain boundaries;

86 4) Discussion on the key mechanisms explaining the corrosion of austenic steels in liquid sodium.

\section{Materials and corrosion conditions}

\subsection{Stainless steel and sodium}

90 The substrate tested is an austenitic stainless steel 316L(N) (provided by Industeel France). The

91 dimensions of the steel specimens were $30 \mathrm{~mm}$ long, $20 \mathrm{~mm}$ wide and $1.5 \mathrm{~mm}$ thick. A $1 \mathrm{~mm}$

92 diameter hole along thickness took place at $3 \mathrm{~mm}$ from edge in the middle of the width. Its

93 composition is given in Table 1. The analysis was performed using induced coupled plasma

94 atomic spectroscopy and glow discharge optical emission spectroscopy for carbon. The grain size

95 is close to $41 \pm 2 \mu \mathrm{m}$ (Fig. 1). Before the corrosion experiments, the specimens were polished in

96 several stages. In order to study the influence of the steel surface roughness on corrosion in liquid

97 sodium, it was decided to stop the mechanical polishing at different stages (1200 and 4000 grit

$98 \mathrm{SiC}$ paper and $1 \mu \mathrm{m}$ diamond suspension). The surface roughness obtained with this procedure

99 was found to have a negligible influence on corrosion in liquid sodium during our trials (average

100 roughness $R a<0.1 \mu \mathrm{m})$. Therefore, the sample surface roughness is not given for the results

101 described below. 
102 High purity sodium (99.95 wt.\%) was provided by Métaux Spéciaux SA. The principal impurities

103 are $[\mathrm{Ca}]<2 \mu \mathrm{g} \cdot \mathrm{g}^{-1},[\mathrm{Cl}]=4 \mu \mathrm{g} \cdot \mathrm{g}^{-1},[\mathrm{Fe}]=1 \mu \mathrm{g} \cdot \mathrm{g}^{-1},[\mathrm{~K}]=4 \mu \mathrm{g} \cdot \mathrm{g}^{-1}$. It also contains traces of $\mathrm{C}$.

104 The quantitative analysis of carbon was not possible in our conditions due to contamination

105 during analysis procedure. However, the experimental conditions of the test were already

106 observed as carburizing for this low carbon steel [18]. The as-received solid sodium is covered

107 with a sodium oxide layer, which is manually removed inside an argon-atmosphere glovebox.

\section{2.2. Experimental conditions}

110 The corrosion tests were run in a static sodium device called CorroNa [2]. The sodium (2.3 $\mathrm{kg})$ is

111 contained in a molybdenum crucible (MLR grade containing 0.7 wt. $\%$ of $\mathrm{La}_{2} \mathrm{O}_{3}$, Plansee), placed

112 in a resistance heated furnace. Molybdenum dissolution in sodium was reported to be negligible

113 in molybdenum-made circuit [12]. The device is set in a purified argon atmosphere (provided by

114 Messer with a purity index 6.0, i.e. less than $3 \mathrm{vpm}$ of $\mathrm{H}_{2} \mathrm{O}$ and $2 \mathrm{vpm}$ of oxygen and purified by

115 zeolite adsorption), inside a glove box to simplify all operations involving preparing the test and

116 handling the liquid metal. During the corrosion tests, the system containing the liquid sodium in

117 contact with pure argon is perfectly sealed off from the argon atmosphere in the glove box.

118 After sodium melting, solid sodium oxides float to the free surface of the liquid metal, probably

119 due to surface tension effects, allowing a first skimming operation to be performed to remove

120 these sodium oxides. The liquid metal is then held at low temperature $\left(105-110^{\circ} \mathrm{C}\right)$ for 3 days.

121 The new floating oxide is then carefully skimmed off from the free surface. An additional

122 purification step is then performed at a high temperature $\left(650^{\circ} \mathrm{C}\right.$ for $\left.72 \mathrm{~h}\right)$, using a zirconium

123 getter immersed in the liquid bath to eliminate any residual oxide and dissolved oxygen. The 
124 estimated dissolved oxygen content obtained after this purification step is $1 \mu \mathrm{g} \cdot \mathrm{g}^{-1}$ at the most.

125 The dissolved zirconium concentration is known to be very low. For instance, at $722^{\circ} \mathrm{C}$, the

126 zirconium solubility in sodium is $0.09 \mu \mathrm{g} \cdot \mathrm{g}^{-1}[19]$.

127 After purification, the liquid sodium bath is cooled to $120^{\circ} \mathrm{C}$ and the zirconium getter is removed.

128 Sodium oxide powder $\left(\mathrm{Na}_{2} \mathrm{O}+14.1\right.$ wt. $\% \mathrm{Na}_{2} \mathrm{O}_{2}$, provided by Alfa Aesar) is added to the liquid

129 sodium in order to obtain an oxygen concentration of $189 \pm 8 \mu \mathrm{g} \cdot \mathrm{g}^{-1}$ (assuming that the initial

130 oxygen concentration in the liquid sodium is equal to zero and that $\mathrm{Na}_{2} \mathrm{O}$ and $\mathrm{Na}_{2} \mathrm{O}_{2}$ are

131 completely dissolved in the liquid $\mathrm{Na}$ ).

132 After this step, in order to keep the oxygen content of the sodium constant, the specimens are

133 immersed in the molten sodium bath at $120^{\circ} \mathrm{C}$ and the system is tightly closed. The sodium is

134 then heated to $650^{\circ} \mathrm{C}$ at a rate of $0.5^{\circ} \mathrm{C} / \mathrm{min}$. The temperature is kept constant for $122 \mathrm{~h}, 250 \mathrm{~h}$

135 and $500 \mathrm{~h}$ before being decreased at a rate of $0.5^{\circ} \mathrm{C} / \mathrm{min}$. The specimens are removed from the

136 liquid sodium at $120^{\circ} \mathrm{C}$. The sodium residues present on the specimens are removed with 99.9

137 wt.\% pure ethanol (provided by Carlo Erba) at ambient temperature. This soft cleaning procedure

138 was chosen to remove the sodium residues from the surface and to keep as much as possible

139 liquid sodium that might have penetrated into the corrosion surface layer during the corrosion

140 processes.

\section{2.3. Characterization techniques}

143 Specimens are weighted before and after the corrosion test, using an AT20 weighing scale

144 constructed by MettlerToledo. X-Ray Diffraction (XRD, Bruker D8 discover) was carried out to

145 characterize the phases formed during corrosion. XRD was performed in the $\theta-2 \theta$ configuration 
146 with a copper cathode emitting X-rays of wavelength $\lambda=1.5406 \AA$. Characterizations were

147 performed by means of Scanning Electron Microscopy (SEM, Zeiss LEO 1460VP) associated

148 with Energy Dispersive X-ray spectroscopy (EDX, SAMX DXP-X10P), to observe and analyse

149 the surfaces and polished cross-sections of the specimens. Elementary depth profiles were

150 obtained from the sample surface using Glow Discharge Optical Emission Spectroscopy

151 (GDOES). The instrument used was a GD-Profiler 2 from the Horiba Scientific company. The

152 glow discharge was powered by a $13.56 \mathrm{MHz}$ radio-frequency generator. A $4 \mathrm{~mm}$-diameter

153 copper anode and 99.9999 vol.\% purity argon gas were used to sputter the sample (800 Pa and 30

$154 \mathrm{~W})$. The emission responses from the excited sputtered elements ( $\mathrm{O}, \mathrm{Fe}, \mathrm{Cr}, \mathrm{Ni}, \mathrm{Mo}, \mathrm{C}, \mathrm{Si}, \mathrm{Mn}$,

155 etc.) were detected using a polychromator with a focal length of $500 \mathrm{~mm}$. A monochromator was

156 used to determine the sodium concentration. The calibration curves used to quantify the metal

157 elements were obtained by using bulk reference materials. The resulting depth in the reference

158 materials was measured with a perthometer (PerthoConcept, Mahr Mesure). The crater depth

159 cartography in the stainless steel was measured using an optical interferometer (Bruker

160 ContourGT). A sample is also observed by Transmission Electron Microscopy (TEM), coupled

161 with an EDX detector. The instruments used are a Tecnai Osiris TEM and a ChemiSTEM EDX

162 detector, contructed both by FEI. The TEM characterizations are performed on a sample prepared

163 by Focused Ion Beam (FIB) on a Strata 400S FIB, constructed by FEI.

164 Three specimens are obtained after $122 \mathrm{~h}$, six after $250 \mathrm{~h}$ and three after $500 \mathrm{~h}$ in the CorroNa

165 static sodium device. All the specimens are weighed before and after the corrosion test and

166 further characterized by GDOES. All the samples obtained after 250 and $500 \mathrm{~h}$ are observed by 
167 SEM and analysed by EDX and DRX. One sample, immersed during $250 \mathrm{~h}$ is prepared by FIB 168 and observed by TEM.

\section{Experimental results highlighting corrosion processes}

171 Figure 2 gives the difference between the sample masses after and before immersion in liquid

172 sodium (positive in case of mass gain and negative in case of mass loss) versus time. The

173 formation of a solid product with impurities and/or sodium leads to a mass gain of the sample

174 while a dissolution phenomena leads to a mass loss. In the test presented here, the sample mass

175 increases after immersion in liquid sodium containing $189 \mu \mathrm{g} \cdot \mathrm{g}^{-1}$ of oxygen during $122 \mathrm{~h}$. At

176 longer immersion time, the sample loses mass when the immersion time increases.

\section{3.1. Morphology and composition of the corrosion products}

179 The surface of a sample immersed during $250 \mathrm{~h}$ is shown in Fig. 3a. The surface features are 180 typical of the characterizations obtained in all conditions. Two morphologies are shown on the 181 sample surface, a dark one and a grey light one.

182 The sample surface is mainly covered with triangle-shaped crystals, rich in chromium, sodium 183 and oxygen (Fig. 3b, EDX analysis of the white cross in Fig. 3a). Iron, nickel and molybdenum 184 are also detected in this area, probably from the steel substrate. Considering the triangle shape [8] 185 combined with the elements detected by EDX and thermodynamic data [20], this phase might be 186 sodium chromite $\mathrm{NaCrO}_{2}$. 
187 The clearer phase is rich in molybdenum and iron (Fig. 3c, EDX analysis of the black cross in

188 Fig. 3a). Chromium and nickel are also detected in this phase, probably from the steel substrate.

\subsection{Nature of the phases formed during corrosion}

191 The different phases described in Section 3.1 were characterized using XRD to determine their

192 chemical nature. The experimental XRD diagram, obtained for the steel sample immersed in

193 liquid sodium at $650^{\circ} \mathrm{C}$ for $500 \mathrm{~h}$, was compared with the theoretical diagram of austenite,

$194 \mathrm{NaCrO}_{2}$ and several $\mathrm{M}_{6} \mathrm{C}$ carbides containing $\mathrm{Cr}$, Mn, Fe, Ni and Mo (Fig. 4). The XRD

195 characterizations confirmed the formation of both sodium chromite $\left(\mathrm{NaCrO}_{2}\right)$ and $\mathrm{M}_{6} \mathrm{C}$ carbides

196 for all the corrosion times. The closer carbide seems to be $\mathrm{Fe}_{3} \mathrm{Mo}_{3} \mathrm{C}$. These characterizations

197 confirm the formation of sodium chromite previously characterized by SEM [13] and clarify the 198 nature of the molybdenum rich phase as $\mathrm{M}_{6} \mathrm{C}$, a molybdenum and iron rich carbide.

199

\subsection{In-depth corrosion}

\subsubsection{Cross-section observations}

202 The cross-section of a sample immersed in liquid sodium for $250 \mathrm{~h}$ at $650^{\circ} \mathrm{C}$ is shown in Fig. 5.

203 This SEM image is obtained in backscattered electron (BSE) mode, in which materials with

204 elements composed of higher atomic number (Z) appear clearer than the one with lower Z

205 elements.

206 At the top of the image, the mounting resin appears in black. At the bottom, the stainless steel 207 appears to be grey. A dark grey layer, corresponding to the sodium chromite layer, is observed 
208 below the mounting resin. This sodium chromite layer seems to be discontinuous in some

209 locations. In between this oxide scale and the steel substrate, cavities (dark areas) are formed. In

210 addition, a lighter grey phase is seen between the Cr-Na-O-rich zone and the top of the cavity

211 zone. This phase might be molybdenum and iron rich carbide $\mathrm{M}_{6} \mathrm{C}$.

212 A grain boundary is visible in the middle of the cross-section. This grain boundary emerges at the

213 steel surface and was probably in contact with liquid sodium at the beginning of the corrosion

214 process. Its upper part is filled with oxide. A cavity is present immediately beneath oxide.

\subsubsection{In-depth concentration profiles}

217 The composition depth profiles of carbon, oxygen, chromium, iron, nickel, molybdenum and

218 sodium obtained through GDOES are plotted together in Figure 6. The element compositions in

$219 \log$-scale are given as a function of depth for the sample corroded for $250 \mathrm{~h}$ at $650^{\circ} \mathrm{C}$ in liquid

220 sodium with an oxygen content of $189 \mu \mathrm{g} \cdot \mathrm{g}^{-1}$. The origin of the $x$-axis corresponds to the

221 specimen surface. The maximum depth of $12 \mu \mathrm{m}$ corresponds to the mean depth of the crater left

222 by the analysis. The scales of the two analyses (GDOES, fig. 6 and SEM, fig. 5) are not an exact

223 match: $5 \mu \mathrm{m}$ in the SEM image corresponds to $4 \mu \mathrm{m}$ in the composition depth profile. This slight

224 difference can be explained by the fact that the composition profiles measured through GDOES

225 are averaged over the $4 \mathrm{~mm}$-diameter area analysed, whereas SEM provides a much more local

226 observation and by the fact that the erosion rate might be slightly different from one phase to the

227 other. In any case, as is shown below, the agreement between the two characterizations is

228 excellent. The different depths cited below are deduced from the GDOES profiles. 
229 At the steel surface, the composition profiles indicate enrichment in oxygen, sodium and

230 chromium in a $1 \mu \mathrm{m}$-thick surface layer, corresponding to the sodium chromite scale (Figs. 4 and

231 5). It should be noted that the oxygen composition decreases whereas the sodium and chromium

232 compositions slightly increases in this oxide scale from the surface to the depth of $1 \mu \mathrm{m}$. The

233 iron, nickel and molybdenum compositions increase in the oxide scale from nearly 0.1 at. $\%$ at the

234 specimen surface to 8,2 and 2 at.\% respectively.

235 The composition profiles under the oxide scale differ from those of the bulk of the steel substrate.

236 The thus affected area corresponds to the presence of corrosion products (Fig. 4 and Fig. 5) and

237 can be divided into two zones. The first zone is located at depths between $1 \mu \mathrm{m}$ and $1.55 \mu \mathrm{m}$

238 beneath the specimen surface. The compositions of molybdenum and carbon rise to a peak of 3.1

239 at. $\%$ and 0.38 at. $\%$ respectively at approximately $1.3 \mu \mathrm{m}$. These composition peaks correspond to

240 the Mo and Fe-rich carbides (light grey phase, Fig. 5). The Cr composition profile presents a

241 slightly depleted zone at around $1.55 \mu \mathrm{m}$. The evolution as a function of immersion time (less

242 than $500 \mathrm{~h}$ ) of the location of the chromium minimum concentration could not be measured

243 because included in the measurement uncertainty $( \pm 0.2 \mu \mathrm{m})$. The second zone is located at

244 depths ranging between 1.55 and $5.25 \mu \mathrm{m}$, with a slight increase in the $\mathrm{Fe}, \mathrm{Cr}$ and $\mathrm{Ni}$

245 compositions to their bulk values and a sharp decrease in the $\mathrm{C}, \mathrm{O}$ and $\mathrm{Na}$ contents. The slope

246 changes in the sodium composition profile (inflexion points indicated by arrows in Fig. 6) are

247 consistent with the characteristic depth of internal oxides and cavities formed underneath at the

248 grain boundaries.

249 Under the affected area, no corrosion products are found in the steel substrate (Fig. 5). However,

250 the $\mathrm{Na}$ and $\mathrm{O}$ contents are not equal to zero and they decrease slightly to their detection limits. 
251 This last segment of the composition profiles, plotted in Log-scale, must be considered with care

252 and could be an artefact of the GDOES measurements because the shape of the sputter crater

253 shows a steadily increasing deviation from its ideal shape upon increasing sputtering time.

254 Additionally, crater edge effects provide a more significant contribution to the overall signal 255 upon increasing crater depth.

256 In the end, it should be reminded that the experimental results described above were obtained for 257 different surface roughnesses, obtained by mechanical polishing stopped at different stages (1200 258 and 4000-grit SiC paper and $1 \mu \mathrm{m}$ diamond suspension). Our tests demonstrated that the 259 corresponding surface roughnesses have no influence on the corrosion mechanisms studied.

\section{Chromium concentration evolution nearby the surface}

262 In the literature, it is demonstrated that oxygen strongly affects the behaviour of chromium by the 263 formation of $\mathrm{NaCrO}_{2}$ [13-17]. That is why the evolution of chromium concentration was analysed 264 close to metallurgical defects such as grain boundaries (section 4.1). The mean chromium 265 concentration was also characterized as a function of immersion time (section 4.2).

\section{4.1. Evolution of chromium concentration along an emerging grain boundary}

268 Thin foils obtained by FIB are useful to measure the local elementary composition by EDX with 269 TEM. This experimental technique is used to characterize chromium composition around a grain 270 boundary. 
271 The HAADF (High-Angle Annular Dark-Field) image of a sample immersed during $250 \mathrm{~h}$ in 272 liquid sodium containing $189 \mu \mathrm{g} \cdot \mathrm{g}^{-1}$ of oxygen at $650^{\circ} \mathrm{C}$ is presented in Fig. 7. The white layer at 273 the top of the image corresponds to a tungsten protecting layer deposited during FIB processing.

274 The dark grey layer below corresponds to the sodium chromite layer. The steel grain boundary is

275 highlighted by a dotted line. Some white spots, corresponding to $\mathrm{M}_{6} \mathrm{C}$ carbides, are visible

276 between the metal and the sodium chromite layer. Cavities are not present on this part of the 277 sample.

278 The red arrows numbered "1" and "2" in Fig. 7 correspond to the location of the chromium EDX 279 analysis shown in Fig. 8. The chromium concentration is plotted as a function of distance from 280 the grain boundary (located at abscissa 0). The measurement length was $100 \mathrm{~nm}$ in the left steel 281 grain and $350 \mathrm{~nm}$ in the right steel grain. The chromium composition decreases from the center of 282 the grains to the grain boundary where it reaches a minimum. The concentration profile 1 exhibits 283 two Cr concentration peaks which might correspond to small phases rich in chromium such as 284 carbides or oxides.

285 Moreover, the chromium concentration of profile 1 is lower than the concentration of profile 2, 286 because the location of profile 1 is closer to the surface.

287 To summarize, the alloy is chromium-depleted around emerging grain boundary, and closer the 288 location is to the steel surface and the grain boundary, higher the chromium depletion is.

290 4.2. Evolution of chromium depletion as a function of immersion time

291 The mean chromium concentration profile measured by GDOES is given as a function of depth in 292 Fig. 9 for three immersion times in liquid sodium (122, 250 and 500 h). For all trials, the origin of 14 
$293 x$-axis is placed at the minimum chromium concentration, assumed to be the interface between

294 steel and corrosion products as discussed before (section 3.3.2). At $10 \mu \mathrm{m}$ depth at the most, the

295 Cr concentration of all samples reaches the initial concentration of the studied steel for the three

296 immersion times. In the following, this steel zone that is not affected by corrosion is called the

297 steel bulk.

298 At the interface between steel and corrosion products, the chromium concentration does not

299 depend on immersion time. From this interface to the bulk, the chromium concentration increases

300 in all cases. The lower chromium concentration is obtained for the samples immersed longer in

301 liquid sodium. The samples immersed during $500 \mathrm{~h}$ are more chromium depleted than the 302 samples immersed during $250 \mathrm{~h}$ which are also more depleted than the samples immersed during $303122 \mathrm{~h}$.

\section{Discussion}

306 In the following sections, a discussion is held concerning the final structure of the corrosion

307 products (Section 5.1) and the mechanisms explaining their formation (Section 5.2).

\section{$308 \quad$ 5.1. Final structure of the corrosion products}

309 As shown in Section 3, during immersion in liquid sodium containing $189 \mu \mathrm{g}^{-\mathrm{g}^{-1}}$ of oxygen at

$310650^{\circ} \mathrm{C}$, the stainless steel studied became covered with a sodium chromite $\left(\mathrm{NaCrO}_{2}\right)$ layer.

311 Molybdenum and iron rich carbides $\left(\mathrm{M}_{6} \mathrm{C}\right)$ are also formed underneath. These observations

312 confirm previous results described in the literature, i.e. formation of sodium chromite [8, 12-16]

313 and carbides [9] in oxidizing and carburizing conditions. 
314 The system studied here is composed of liquid sodium containing traces of dissolved oxygen and

315 carbon in contact with a stainless steel containing Cr, Fe and Mo. Thermodynamic calculations

316 described below will show that $\mathrm{NaCrO}_{2}$ and $\mathrm{M}_{6} \mathrm{C}$ are equilibrium phases in such a system.

\section{$318 \quad$ 5.1.1. Oxides' stability}

319 Three main solid oxides can be formed at the steel surface or in liquid sodium: sodium chromite

$320\left(\mathrm{NaCrO}_{2}\right)$, sodium ferrate $\left(\mathrm{Na}_{4} \mathrm{FeO}_{3}\right)[21]$ and sodium oxide $\left(\mathrm{Na}_{2} \mathrm{O}\right)$.

321 At the steel surface, the chemical reaction corresponding to solid $\mathrm{Na}_{x} \mathrm{MO}_{y}$ formation can be

322 written as follows:

323

$[0]+\frac{x}{y} \cdot \mathrm{Na}_{\text {liq }}+\frac{1}{y} \cdot \mathrm{M}_{\text {steel }} \rightarrow \frac{1}{y} \mathrm{Na}_{x} \mathrm{MO}_{y}$

(Eq. 1)

324 where $\mathrm{M}_{\text {steel }}=\mathrm{Fe}$ or Cr in solid solution in steel, $x$ and $y$ are the stoichiometric coefficients of

$325 \mathrm{Na}_{x} \mathrm{MO}_{y}$ and [0] corresponds to oxygen dissolved in liquid sodium.

326 The reference state is chosen to be pure liquid sodium, pure body-centered cubic solid $\mathrm{M}$ and

327 pure $\mathrm{O}_{2}$ at standard pressure of 1.013 bar. At thermodynamic equilibrium, the law of mass action

328 is given by:

$\mu_{[O]}=\frac{1}{y} \cdot\left(\Delta G_{f, N a_{x} M O_{y}}^{0}+R T \cdot \ln \frac{a_{N a_{x} M O_{y}}}{a_{M} \cdot a_{N a^{x}}}\right)$

(Eq. 2)

330 where $\mu_{[O]}$ is the chemical potential of oxygen in liquid sodium, $\Delta G_{f, N a_{x} M O_{y}}^{0}$ is the standard

331 Gibbs free energy of formation of $\mathrm{Na}_{x} \mathrm{MO}_{y}, R$ is the gas constant $\left(R=8.314 \mathrm{~J} \cdot \mathrm{mol}^{-1} \cdot \mathrm{K}^{-1}\right), T$ is the

332 temperature, $a_{N a_{x} M O_{y}}, a_{M}$ and $a_{N a}$ are the activities of $\mathrm{Na}_{x} \mathrm{MO}_{y}, \mathrm{M}$ and $\mathrm{Na}$ respectively. 
333 As a first approximation, liquid sodium and the oxides formed can be considered to be pure, i.e.,

$334 a_{N a}=1$ and $a_{N a_{x} M O_{y}}=1$. The activities of $\mathrm{Fe}$ and $\mathrm{Cr}$ in austenite are calculated as a function of

335 temperature by means of the CALPHAD method implemented in ThermoCalc ${ }^{\circledR}$, with the TCFE8

336 (Steels/Fe-Alloys v8.0) database. For instance, at $650^{\circ} \mathrm{C}, a_{F e}=0.67$ and $a_{C r}=0.28$, in using the

337 reference as pure stable metal (body-centered cubic for chromium and iron). The steel

338 composition used for the calculation is limited to the main elements $(\mathrm{Cr}, \mathrm{Ni}, \mathrm{Mo}, \mathrm{Mn}, \mathrm{C}, \mathrm{Si}$ and

$339 \mathrm{Fe})$. The contents of $\mathrm{Cr}, \mathrm{Ni}, \mathrm{Mo}, \mathrm{Mn}, \mathrm{C}$ and $\mathrm{Si}$ are the ones given in Table 1 and the balanced $\mathrm{Fe}$

340 content is slightly higher than in the real stainless steel. This choice was made because the

341 calculation including the minor elements did not converge. With this choice, the activities of the

342 chosen elements are supposed to be weakly dependent on minor elements. This seems quite

343 reasonable for $\mathrm{Cr}$ and $\mathrm{Fe}$ which are the only ones considered for the oxides' formation $\left(\mathrm{NaCrO}_{2}\right.$

344 and $\mathrm{Na}_{4} \mathrm{FeO}_{3}$ ). The $\mathrm{Cr}$ and $\mathrm{Fe}$ contents are indeed much higher than those of the other elements.

345 The standard Gibbs free energy of formation (in $\left.\mathrm{kJ} . \mathrm{mol}^{-1}\right)$ of $\mathrm{NaCrO}_{2}(-874.6+0.20921 . T)$ and

$346 \mathrm{Na}_{4} \mathrm{FeO}_{3}(-1214.17+0.34269 . T)$ are given in Ref. [20] as a function of temperature $T$ in $\mathrm{K}$. The

347 relative stability of both oxides can be shown in the Ellingham diagram presented in Fig. 10a.

348 The chemical potential of oxygen in liquid sodium given by Eq. 2 is plotted as a function of

349 temperature for $\mathrm{Na}_{4} \mathrm{FeO}_{3}$ (purple line) and $\mathrm{NaCrO}_{2}$ (blue line). The oxide is spontaneously

350 formed in the region above the corresponding straight line.

351 In liquid sodium, the chemical reaction corresponding to solid $\mathrm{Na}_{2} \mathrm{O}$ formation can be written as 352 follows:

$353[0]+2 \cdot \mathrm{Na}_{\text {liq }} \rightarrow \mathrm{Na}_{2} \mathrm{O}$

354 At thermodynamic equilibrium, the law of mass action leads to: 
$\mu_{[O]}=\Delta G_{f, N a_{2} O}^{0}+R T \cdot \ln \frac{a_{N a_{2} O}}{a_{N a^{2}}}$

(Eq. 4)

356 where $\Delta G_{f, N a_{2} O}^{0}\left(=-421.5+0.1414 . T\right.$ in $\left.\mathrm{kJ}^{\circ} \mathrm{mol}^{-1}[22]\right)$ is the standard Gibbs free energy of

357 formation of $\mathrm{Na}_{2} \mathrm{O}$ and $a_{\mathrm{Na}}=1$. If $\mathrm{Na}_{2} \mathrm{O}$ is supposed to be pure, $a_{\mathrm{N} a_{2} \mathrm{O}}=1$. In this case, the

358 chemical potential of oxygen in liquid sodium given by Eq. 4 is represented by the black straight

359 line in the Ellingham diagram (Fig. 10a). $\mathrm{Na}_{2} \mathrm{O}$ is spontaneously formed in the region above this

360 straight line.

361 The chemical potential of oxygen in liquid sodium must be calculated in the conditions studied

362 here (i.e., $[\mathrm{O}]=189 \mu \mathrm{g} \cdot \mathrm{g}^{-1}$ and $650^{\circ} \mathrm{C}$ ), in order to determine if the oxides considered above

$363\left(\mathrm{Na}_{4} \mathrm{FeO}_{3}, \mathrm{NaCrO}_{2}\right.$ and $\left.\mathrm{Na}_{2} \mathrm{O}\right)$ are stable.

$364 \mu_{[O]}=R \cdot T \cdot \ln a_{[O]}$

365 where $a_{[0]}$ is the activity of oxygen in liquid sodium, the reference state being pure $\mathrm{O}_{2}$ at

366 standard pressure of 1.013 bar. The solubility of oxygen in sodium $w_{[0]}^{N a, s a t}$ can be found in the

367 literature [23] $\left(\log w_{[0]}^{N a, s a t}=6.2571-\frac{2444.5}{T}\right.$ in $\left.\mu \mathrm{g} \cdot \mathrm{g}^{-1}\right)$. It can therefore be convenient to define

368 the activity of oxygen in liquid sodium $a_{[O]}^{\prime}$ with the reference state of liquid sodium saturated in

369 oxygen (i.e., $a_{[0]}^{\prime}=1$ for oxygen-saturated liquid sodium).

370 Oxygen is present in small quantities in liquid sodium, in the form of a dilute solution (at $650^{\circ} \mathrm{C}$,

$371 w_{[\mathrm{O}]}^{N a \text { sat }}=0.4 \mathrm{wt} . \%$ or $\left.x_{[\mathrm{O}]}^{N a, \text { sat }}=0.6 \mathrm{~mol} . \%\right)$. As currently done for oxygen in liquid iron [24],

372 Henry's law can be used to express the activity of oxygen in liquid sodium:

$373 a_{[0]}^{\prime}=\gamma_{[O]}^{\circ} \cdot x_{[0]}$

(Eq. 6) 
374 where $\gamma_{[O]}^{\circ}$ is the Henry's law constant and $x_{[O]}$ the mole fraction of oxygen in liquid sodium.

375 Assuming that Henry's law is validated for oxygen content lower than or equal to its solubility in

376 liquid sodium:

$377 \quad \gamma_{[0]}^{\circ}=\frac{1}{x_{[0]}^{N a, s a t}}$

378 and

$379 \quad a_{[O]}^{\prime}=\frac{x_{[O]}}{x_{[0]}^{N a, s a t}}$

380 As the oxygen content is low in liquid sodium, the activity of oxygen is also given by:

$381 \quad a_{[O]}^{\prime}=\frac{w_{[O]}}{w_{[0]}^{N a, s a t}}$

382 Finally,

$383 \mu_{[O]}=R \cdot T \cdot \ln a_{[O]}=R \cdot T \cdot \ln a_{[O]}^{\prime}+\Delta G_{d i s s}$

(Eq. 10)

384 where $\Delta G_{\text {diss }}$ is the Gibbs free energy change for the chemical reaction

$385 \quad \frac{1}{2} \mathrm{O}_{2(\text { gas })} \rightarrow[\mathrm{O}]_{\mathrm{Na}_{\text {liq }}^{\text {sat }}}$

386 with $[\mathrm{O}]_{\mathrm{Na}_{l i q}}^{\text {sat }}$ the oxygen dissolved in liquid sodium at saturation.

387 To our knowledge, there is no measurement of $\Delta G_{\text {diss }}$ in the literature. Fig. $10 \mathrm{~b}$ represents the

388 Gibbs free energy of formation of Na-O binary phases as a function of mole fraction of oxygen

$389 x_{[0]}$ at a particular temperature $T$, the reference state being pure liquid sodium and pure $\mathrm{O}_{2}$ gas.

390 The general case is schematized in blue. The Gibbs free energy of formation of Na-O liquid

391 phase is represented by the blue curve. The coordinates of the point corresponding to $\mathrm{Na}_{2} \mathrm{O}$ are

$392 x_{[\mathrm{O}]}=\frac{1}{3}$ and $\frac{1}{3} \cdot \Delta G_{f, N a_{2} O}^{0}$. When $\mathrm{Na}_{2} \mathrm{O}$ is in equilibrium with the liquid phase, the point 
corresponding to $\mathrm{Na}_{2} \mathrm{O}$ belongs to the straight line tangent to the liquid phase curve at the

394 composition $x_{[0]}^{N a, s a t}$. This tangent line cuts the $x_{[O]}=1$ axis at the ordinate $R \cdot T \cdot \ln a_{[O]}^{N a, s a t}$, where

$395 a_{[0]}^{\mathrm{Na,sat}}$ is the activity of oxygen in liquid sodium in equilibrium with $\mathrm{Na}_{2} \mathrm{O}$. This intersect also

396 corresponds to the origin of the $a_{[0]}^{\prime}$ scale (i.e., R.T. $\ln a_{[0]}^{\prime}=0$, Eq.8). The corresponding

$397 \Delta G_{\text {diss }}$ is then given by Eq. 10 written in this particular case:

$398 \mu_{[O]}=R \cdot T \cdot \ln a_{[O]}^{N a, s a t}=\Delta G_{d i s s}$

399 If the oxygen content $x_{[0]}$ in liquid Na is less than $x_{[0]}^{N a, s a t}$, the red tangent line (Fig. 10b) to the

400 liquid phase curve cuts the $x_{[O]}=1$ axis at the ordinate $R . T \cdot \ln a_{[O]}$. The different terms of Eq. 10,

401 in particular R.T. $\ln {a^{\prime}}_{[0]}$, can be determined as shown in Fig. 10b.

402 The value of $\Delta G_{\text {diss }}$ depends on the shape of the Gibbs free energy of formation of Na-O liquid

403 phase which is unknown. As oxygen is dissolved in liquid $\mathrm{Na}, \Delta G_{\text {diss }} \leq 0$. Another limiting case

404 is presented in Fig.10b, with the blue dashed line. It corresponds to the mimimum value of the

405 Gibbs free energy of formation of Na-O liquid phase at $x_{[0]}^{N a, s a t}$ and therefore the maximum value

406 of $\Delta G_{\text {diss. }}$. Using Thales' theorem,

$407 \Delta G_{\text {diss }}>\Delta G_{f, N a_{2} O}^{0}$

(Eq. 13)

408 Finally, with the real shape of the Gibbs free energy of formation of Na-O liquid phase,

$409 \Delta G_{f, N a_{2} O}^{0}<\Delta G_{d i s s}<0$

410 At $650^{\circ} \mathrm{C},-290988<\Delta G_{\text {diss }}<0\left(\mathrm{~J} \mathrm{~mol}^{-1}\right)$. 
411 As liquid sodium is almost pure, the activity of $\mathrm{Na}$ in liquid sodium can be expressed by Raoult's

412 law. With this assumption, the solid blue line described above cuts the $x_{[\mathrm{O}]}=0$ axis at the

413 ordinate $R \cdot T \cdot \ln \left(1-x_{[0]}^{N a, s a t}\right)$ and the $x_{[0]}=1$ axis at the ordinate given by:

$414 \mu_{[O]}=\Delta G_{f, N a_{2} O}^{0}-2 R \cdot T \cdot \ln \left(1-x_{[0]}^{N a, s a t}\right)=\Delta G_{d i s s}$

415 For instance, at $650^{\circ} \mathrm{C}$, the solid blue line cuts the $x_{[o]}=0\left(\right.$ resp. $\left.x_{[o]}=1\right)$ axis at $-45 \mathrm{~J} \mathrm{~mol}^{-1}$

416 (resp. -290898 $\mathrm{J} \mathrm{mol}^{-1}$ ). Finally, $\Delta G_{\text {diss }}$ can be estimated by $\Delta G_{f, N a_{2} O}^{0}$ since the relative

417 uncertainty induced by this approximation is less than $0.05 \%$ in the temperature range [400;

$\left.418700^{\circ} \mathrm{C}\right]$. This means that the tangent line to the liquid phase curve at the composition $x_{[0]}^{N a, s a t}$ is close

419 to the blue dashed line.

420 In Fig. 10a, $\mu_{[O]}=R . T . \ln a_{[o]}($ Eq. 10) is plotted for different oxygen contents in liquid sodium

421 and $\Delta G_{\text {diss }}=\Delta G_{f, N a_{2} O}^{0}$. Let us first consider the curve corresponding to an oxygen content of

$4221000 \mu \mathrm{g} \cdot \mathrm{g}^{-1}$. The calculation predicts that solid $\mathrm{Na}_{2} \mathrm{O}$ is in equilibrium with liquid sodium

423 containing $1000 \mu \mathrm{g} \cdot \mathrm{g}^{-1}$ for temperatures less than $751 \mathrm{~K}$. This is in good agreement with

424 measurements found in the literature [23]. This means that the unknown value $\Delta G_{\text {diss }}$ can be

425 approximated by $\Delta G_{f, N a_{2} O}^{0}$ (as was done before [21]). For an oxygen concentration of $189 \mu \mathrm{g} \cdot \mathrm{g}^{-1}$

426 in liquid sodium (red $\mu_{[0]}$ curve, Fig. 10a), at temperatures higher than $350^{\circ} \mathrm{C}$, the chemical

427 potential of oxygen is lower than the one required to form $\mathrm{Na}_{2} \mathrm{O}$ or $\mathrm{Na}_{4} \mathrm{FeO}_{3}$ and higher than the

428 one required to form $\mathrm{NaCrO}_{2}$. It implies that in our experimental conditions, i.e., $650{ }^{\circ} \mathrm{C}$ and

$429189 \mu \mathrm{g} \cdot \mathrm{g}^{-1}$ of oxygen, the sodium chromite formation is thermodynamically possible while the

430 formation of sodium oxide and sodium ferrate is not possible. 


\subsubsection{Carbides' stability}

433 The carbides' stability is also investigated by means of ThermoCalc ${ }^{\circledR}$ based on CALPHAD 434 method, with the TCFE8 (Steels/Fe-Alloys v8.0) database. As for the calculations of the oxides' 435 stability, the steel composition is limited to the main elements in austenite $(\mathrm{Cr}, \mathrm{Ni}, \mathrm{Mo}, \mathrm{Mn}, \mathrm{C}, \mathrm{Si}$ 436 with the contents given in Table 1 and Fe with a content slightly higher than in the real stainless 437 steel). The carbides considered are $\mathrm{M}_{23} \mathrm{C}_{6}, \mathrm{M}_{3} \mathrm{C}_{2}, \mathrm{M}_{5} \mathrm{C}_{2}, \mathrm{M}_{6} \mathrm{C}, \mathrm{M}_{7} \mathrm{C}_{3}$, where $\mathrm{M}$ can be $\mathrm{Cr}, \mathrm{Mn}, \mathrm{Fe}$, $438 \mathrm{Ni}$ and Mo. The activity of the elements in austenite in equilibrium with carbides is essentially 439 unchanged (lower than 1 hundredth) compared to the activity of the elements in austenite (used in 440 section 5.1.1).

441 Fig. 11a gives the results of the mole fraction of stable phases as a function of temperature. The 442 mole fraction of austenite is closed to 1 for all temperatures. The most stable carbide is $\mathrm{M}_{6} \mathrm{C}$ for 443 temperatures below $615{ }^{\circ} \mathrm{C}\left(\mathrm{M}_{23} \mathrm{C}_{6}\right.$ also exists but at a very low molar fraction less than $\left.10^{-3}\right)$ and $444 \quad \mathrm{M}_{23} \mathrm{C}_{6}$ for temperatures higher than $650{ }^{\circ} \mathrm{C}$ (together with $\mathrm{M}_{6} \mathrm{C}$ at a very low molar fraction). In 445 between, both carbides are present. Fig. $11 \mathrm{~b}$ and Fig. 11c present the elemental composition of $446 \mathrm{M}_{6} \mathrm{C}$ and $\mathrm{M}_{23} \mathrm{C}_{6}$ carbides. $\mathrm{M}_{6} \mathrm{C}$ carbides contain mainly $\mathrm{Mo}, \mathrm{Fe}$ and $\mathrm{C}$ and $\mathrm{M}_{23} \mathrm{C}_{6}$ carbides mainly $447 \mathrm{Cr}$ and $\mathrm{C}$. At $650^{\circ} \mathrm{C}$, the carbides formed in the stainless steel studied here are rich in Mo and the 448 XRD peaks are consistent with $\mathrm{M}_{6} \mathrm{C}$ carbides containing mainly $\mathrm{Mo}$, $\mathrm{Fe}$ and $\mathrm{C}$ (such as $\mathrm{Fe}_{3} \mathrm{Mo}_{3} \mathrm{C}$ ) 449 and in small proportions $\mathrm{Cr}$, $\mathrm{Mn}$ and $\mathrm{Ni}$. At $650{ }^{\circ} \mathrm{C}$, the $\mathrm{M}_{6} \mathrm{C}$ composition given by 450 thermodynamic calculations is close to $\mathrm{Mo}_{4} \mathrm{Fe}_{2} \mathrm{C}$ (Fig. 11b) (Mo: 48 at.\%, Fe: 29.3 at.\%, C: 14.3 451 at.\%, Cr: 8 at.\%). It can therefore be concluded that the $\mathrm{M}_{6} \mathrm{C}$ carbides formed are in 452 thermodynamic equilibrium in the system, even if the calculated maximum temperature for $\mathrm{M}_{6} \mathrm{C}$ 
453

454

455

456

457

458

459

460

461

462

463

464

465

466

467

468

469

470

471

472

473

stability is less than $650{ }^{\circ} \mathrm{C}$ (Fig. 11a). This temperature could be slightly underestimated by the calculations.

\subsection{Mechanisms and driving forces of corrosion phenomena}

Corrosion tests in liquid sodium containing $189 \mu \mathrm{g} \cdot \mathrm{g}^{-1}$ of oxygen at $650^{\circ} \mathrm{C}$ pointed out the formation of corrosion products composed of sodium chromite $\mathrm{NaCrO}_{2}$ and $\mathrm{M}_{6} \mathrm{C}$ carbides containing Mo and Fe (Fig. 4). The observation of cross sections showed that cavities are formed between these corrosion products and the stainless steel (Fig. 5). Finally, a dissolution of the stainless steel is highlighted by the mass loss measured for immersion durations of 250 and $500 \mathrm{~h}$ (Fig. 2).

The oxidation and carburation mechanisms are described in Section 5.2.1, the dissolution driving forces in Section 5.2.2 and the cavities formation mechanisms in Section 5.2.3..

\subsubsection{Oxidation and carburation mechanisms}

\section{Selective oxidation}

The stainless steel surface under study became covered with a $\mathrm{NaCrO}_{2}$ scale during immersion in liquid sodium. This is a selective oxidation phenomenon, chiefly external, i.e. it occurs on the stainless steel surface (Fig. 5). From a depth of $10 \mu \mathrm{m}$ and moving towards the steel surface, the general shape of the chromium profiles exhibit an initial, constant concentration zone that corresponds to the concentration in the stainless steel bulk then a concentration decrease down to minimum concentration (depletion zone) and, finally, an increase in concentration towards the 
surface (Fig. 9). The concentration profiles obtained are the result of $\mathrm{Cr}$ selective oxidation with Cr diffusion from the steel bulk to the $\mathrm{NaCrO}_{2} /$ steel interface (depth $=0$, Fig. 9) and $\mathrm{NaCrO}_{2}$ formation on the steel surface (depth $<1 \mu \mathrm{m}$, Fig. 9). The mimimum $\mathrm{Cr}$ concentration remains more or less constant at approximately $12 \pm 1$ at. $\%$ from 122 to $500 \mathrm{~h}$ (average and uncertainty on all specimen). This concentration could correspond to $\mathrm{Cr}$ concentration in the stainless steel at equilibrium with $\mathrm{NaCrO}_{2}$. However, caution should be exercised with the conclusion about this particular issue, as a rough thermodynamic assessment would rather give a $\mathrm{Cr}$ concentration in equilibrium with $\mathrm{NaCrO}_{2}$ close to the null value [28] and precise experimental data are still lacking. Indeed, it should be mentioned that the measurement of the $\mathrm{Cr}$ concentration by GDOES probably lacks of accuracy. This is a mean $\mathrm{Cr}$ concentration measured by sputtering the elements in a $4 \mathrm{~mm}$ diameter crater with the contribution of the different corrosion products. For instance, tiny carbides (Fig. 8) contribute as well to the Cr concentration.

In Fig. 9, the shape of $\mathrm{Cr}$ concentration profiles is characteristic of diffusion in polycrystalline materials [25-28], with the influence of the presence of grain boundaries (e.g., from 1.6 to $4.6 \mu \mathrm{m}$ at $500^{\circ} \mathrm{C}$ ). This is confirmed by the $\mathrm{Cr}$ concentration profiles measured in the vicinity of grain boundaries (Fig. 8). Cr depletion is larger in the grain boundary than in the adjacent grains. This result indicates that the $\mathrm{Cr}$ diffusion coefficient is higher in the grain boundary than in the grain (grain boundaries are known to be diffusion short-circuits [32]). In Fig.8, the local Cr concentration decreases from the steel bulk (profile 2) to the surface (profile 1). This is in good agreement with the mean Cr concentration profiles measured by GDOES as described just before.

Finally, $\mathrm{NaCrO}_{2}$ is formed by the reaction of chromium diffusing from the steel bulk with two components of liquid metal, namely sodium and dissolved oxygen. The oxidation front can be 
496 located either at the $\mathrm{NaCrO}_{2} /$ steel interface or $\mathrm{NaCrO}_{2} /$ liquid metal interface. The experiments

497 presented here do not show where the oxidation front is located. Some prior results at $550^{\circ} \mathrm{C}$ are

498 reported in the literature [28], indicating an inner oxidation front.

\section{Carbides formation}

$501 \mathrm{M}_{6} \mathrm{C}$ carbides rich in $\mathrm{Fe}$ and $\mathrm{Mo}$ were present in between the $\mathrm{NaCrO}_{2}$ scale and the stainless steel

502 after immersion in liquid sodium (Fig. 5). Mo segregates to the steel surface where it reacts with

503 Fe from the steel and dissolved $\mathrm{C}$ present in liquid sodium. The experimental conditions of the

504 test were already observed as carburizing for this low carbon steel [18], probably because of high

505 carbon content due to the fabrication process of the sodium metal. Carbon diffuses into the steel

506 matrix and precipitates into carbides representative of the local composition : Mo rich carbide

507 (peak at $1.5 \mu \mathrm{m}$ in Fig. 6), or Fe-Cr rich carbides (peak at $2.8 \mu \mathrm{m}$ in Fig. 6). The Mo

508 concentration profiles obtained present a slight depletion zone (around $2 \mu \mathrm{m}$ in Fig. 6), due to the

509 formation of Mo rich carbides. Carbides could be formed before, at the same time or after

$510 \mathrm{NaCrO}_{2}$. As they were detected under $\mathrm{NaCrO}_{2}$ for all corrosion times investigated, it is not

511 possible to deduce from the experiments where the carburization front is located

\section{$513 \quad$ 5.2.2. Driving force of dissolution}

514 It was shown that the mass of the stainless steel samples decreased during immersion in liquid

515 sodium for 250 and $500 \mathrm{~h}$ (Fig. 2). This means that the stainless steel substrate and / or the

516 chromite scale are dissolved in parallel with the formation of chromite and carbides. The

517 dissolution of the main elements of stainless steel, namely $\mathrm{Fe}, \mathrm{Ni}, \mathrm{Cr}$ and $\mathrm{Mn}$, was already 25 
518 reported to occur in liquid sodium, mainly at low oxygen levels (section 1) [4-7]. The Fe and $\mathrm{Ni}$

519 depletion observed at the metal / oxide interface (Fig. 6) is due to their dissolution in liquid 520 sodium.

521 Considering the principal elements in the stainless steel chosen (table 1), the driving force of

522 dissolution is a function of the $\mathrm{Fe}, \mathrm{Cr}, \mathrm{Ni}, \mathrm{Mn}$ and Mo concentrations in liquid sodium at 523 equilibrium with steel:

$524 \quad \mathrm{M}_{\text {steel }} \leftrightarrow \mathrm{M}_{\mathrm{Na}}$ (Eq. 16)

525 where $\mathrm{M}_{\text {steel }}$ means $\mathrm{M}$ in solid solution in steel and $\mathrm{M}_{\mathrm{Na}}$ is $\mathrm{M}$ dissolved in liquid sodium, $\mathrm{M}$ 526 being $\mathrm{Fe}, \mathrm{Cr}, \mathrm{Ni}, \mathrm{Mn}$ or Mo. These equilibrium concentrations can be estimated using the 527 solubility of the elements in liquid sodium and their activities in the steel if one assumes that the 528 solubility of one dissolved element does not change in presence of the others (we made this 529 strong assumption because of a lack of more precise data). The solubility of $\mathrm{M}$ in sodium $530 w_{\mathrm{M}}^{N a, \text { sat }}$ (in $\mu \mathrm{g} \cdot \mathrm{g}^{-1}$ ) can be found in the literature (Fe [11], Cr [10], Ni [30], Mn [29] and Mo 531 [19]). The solubility of $M$ is defined as the $M$ concentration in liquid sodium at equilibrium with 532 pure stable solid M (body-centered cubic Fe, $\mathrm{Cr}, \mathrm{Mn}$ and $\mathrm{Mo}$, face-centered cubic $\mathrm{Ni}$ at $650^{\circ} \mathrm{C}$ ). At $650^{\circ} \mathrm{C}, w_{\mathrm{Fe}}^{N a, s a t}=1.9 \mu \mathrm{g} \cdot \mathrm{g}^{-1}, w_{\mathrm{Cr}}^{N a, s a t}=0.41 \mu \mathrm{g} \cdot \mathrm{g}^{-1}, w_{\mathrm{Ni}}^{N a, s a t}=2.4 \mu \mathrm{g} \cdot \mathrm{g}^{-1}, w_{\mathrm{Mn}}^{N a, s a t}=1.4 \mu \mathrm{g} \cdot \mathrm{g}^{-1}$

534 and $w_{\text {Mo }}^{N a, s a t}=2.3 \mu \mathrm{g} \cdot \mathrm{g}^{-1}$. As in section 5.1.1., the activities of $\mathrm{Fe}, \mathrm{Cr}, \mathrm{Ni}, \mathrm{Mn}$ and $\mathrm{Mo}$ in austenite 535 were calculated by means of the CALPHAD method in ThermoCalc ${ }^{\circledR}$ with the TCFE8 database. 536 At $650^{\circ} \mathrm{C}, a_{\mathrm{Fe}}=0.67, a_{\mathrm{Cr}}=0.28, a_{\mathrm{Ni}}=0.054, a_{\mathrm{Mn}}=0.0043$ and $a_{\mathrm{Mo}}=0.067$, the reference 537 being pure stable metals. 
$538 \mathrm{M}$ is present in small quantity in liquid sodium. As currently done in liquid iron [24], Henry's law

539 can be used to express the activity of $\mathrm{M}$ in liquid sodium:

$540 \quad a_{\mathrm{M}}^{\mathrm{Na}}=\gamma_{\mathrm{M}} \cdot x_{\mathrm{M}}^{\mathrm{Na}}$

541 where $\gamma_{\mathrm{M}}$ is the Henry's law constant for $\mathrm{M}$ and $x_{\mathrm{M}}^{\mathrm{Na}}$ is the mole fraction of $\mathrm{M}$ in liquid sodium.

542 Assuming that Henry's law is valid for M content lower than or equal to its solubility in liquid

543 sodium, the following equation can be written based on the definition of solubility reminded

544 before (equilibrium between liquid sodium containing the $\mathrm{M}$ mole fraction $x_{\mathrm{M}}^{N a, s a t}$ and pure $\mathrm{M}$ ):

$545 \quad \gamma_{\mathrm{M}} \cdot x_{\mathrm{M}}^{N a, s a t}=1$

546 And therefore $a_{\mathrm{M}}^{\mathrm{Na}}=\frac{x_{\mathrm{M}}^{N a}}{x_{\mathrm{M}}^{N a, s a t}}$

547 As the $\mathrm{M}$ content in liquid sodium is low, the activity of $\mathrm{M}$ in liquid sodium is also given by:

$548 \quad a_{\mathrm{M}}^{\mathrm{Na}}=\frac{w_{\mathrm{M}}^{N a}}{w_{\mathrm{M}}^{N a, s a t}}$

549 Finally, the equilibrium between stainless steel and liquid sodium leads to:

$550 \quad a_{\mathrm{M}}=a_{\mathrm{M}}^{\mathrm{Na}}=\frac{w_{\mathrm{M}}^{N a}}{w_{\mathrm{M}}^{N a, s a t}}$

551 Based on this result, the maximum theoretical mass dissolved in liquid sodium (section 2.2) in the

552 CorroNa device is:

$553 \max \left(M_{\text {dissolved }}^{\mathrm{Na}}\right)=\sum_{M} \frac{M_{\mathrm{Na}} \cdot w_{\mathrm{M}}^{\mathrm{Na} \text {,sat }} \cdot a_{M}}{N_{\text {samples }} \cdot S_{\text {sample }}}$

554 where $M_{\mathrm{Na}}$ is the sodium mass contained in the CorroNa crucible $(2.3 \mathrm{~kg}), N_{\text {samples }}$ is the

555 number of samples immersed in liquid sodium at the same time (6) and $s_{\text {sample }}$ the sample 
556 surface area $\left(0.12 \mathrm{dm}^{2}\right.$ for 2 faces $)$. For the experiments performed here, it corresponds to 4.5

557 mg.dm ${ }^{-2}$.

558 This theoretical mass loss is in good agreement with the one obtained after $250 \mathrm{~h}$ of immersion.

559 However, it is twice less than the one measured for samples immersed for $500 \mathrm{~h}$. The data used to

560 determine the solubilities of each element (Fe [11], Cr [10], Ni [30], Mn [29] and Mo [19]) were

561 proposed for pure metals in pure sodium. In our case, oxygen is present in sodium and might

562 have modified these solubilities as suggested for chromium [19] and iron [4, 10, 11]. The

563 solubilities of chromium and iron are higher in sodium containing oxygen than in pure sodium

564 because some oxides are formed $\left(\mathrm{NaCrO}_{2}, \mathrm{Na}_{4} \mathrm{FeO}_{3}\right)$. Therefore, the stainless steel under

565 investigation might be dissolved in sodium more than the value calculated above. Consequently,

566 the mass loss measured here is higher than expected in pure sodium.

\subsubsection{Cavities formation}

569 In our experiments of corrosion in liquid sodium, cavities were observed at the interface between

570 steel and $\mathrm{NaCrO}_{2}$ scale (Fig. 5).

571 It is well known that an oxide scale growth at high temperature is sometimes accompanied by a

572 void formation within the metal [31-33]. In such a system, vacancies are created in the metal and

573 the vacancy supersaturation can lead to void formation by nucleation mainly on singularities such

574 as grain boundaries or interfaces. If vacancies are all annihilated at sinks like dislocations, they

575 do not cause void formation within the metal and the oxide / metal interface will translate to

576 consume the metal. Two sources of vacancies are described in the literature. First, the removal of

577 cations from the metal due to the growth of the oxide scale creates cationic vacancies at the 28 
578 oxide / metal interface. Secondly, vacancies can also be created by the so-called Kirkendall

579 effect: when the diffusivities of the different elements in the metal are different from each other, a

580 vacancy flux is obtained in the opposite direction of the flux of the fastest element. This

581 Kirkendall vacancy flux is oriented from the metal / oxide interface to the metal bulk (resp. from

582 the metal bulk to the metal / oxide interface) when the selective oxidized element is the fastest

583 (resp. the slowest) diffusing species in the alloy, leading to pores formation in the bulk of the

584 alloy (resp. under the oxide scale). This is the case of high temperature oxidation of Ni-Cr alloys

585 forming chromia scales in which $\mathrm{Cr}$ diffuses much faster than $\mathrm{Ni}$ [34] (resp. Ni-Al with

$586 \mathrm{Al}<50 \mathrm{~mol} . \%$, forming $\mathrm{Al}_{2} \mathrm{O}_{3}$ scales in which $\mathrm{Al}$ diffuses slower than $\left.\mathrm{Ni}[35]\right)$.

587 In the case studied here, vacancies are created at the steel / $\mathrm{NaCrO}_{2}$ interface by $\mathrm{Cr}$ oxidation, 588 carburization (Section 5.2.1) and dissolution of the other elements present in the stainless steel

589 (Section 5.2.2). The vacancies become supersaturated and this leads to the nucleation of the

590 cavities observed (Fig. 5).

591 In the cross section presented in Fig. 5 (which is representative of the whole sample), the large 592 cavities are $11.5 \mu \mathrm{m}$ apart from each other. This can be used to estimate the surface density of 593 cavities $\left(f_{\text {cavities }}=7 \cdot 6 \cdot 10^{-3} \mu \mathrm{m}^{-2}\right)$. Assuming that cavities are only due to chromium departure, the 594 thickness of $\mathrm{NaCrO}_{2}$ formed with the chromium creating the cavities is then given by:

$$
e_{\mathrm{NaCrO}_{2}}=V_{\text {cavity }} f_{\text {cavities }} \frac{\rho_{\mathrm{Cr}}}{\rho_{\mathrm{NaCrO}_{2}}} \frac{M_{\mathrm{NaCrO}_{2}}}{M_{\mathrm{Cr}}}
$$

596 where $V_{\text {cavity }}$ is the mean volume of a cavity supposed to be spherical $\left(7.2 \mu \mathrm{m}^{3}\right), \rho_{C r}$ the 597 chromium density $\left(7150 \mathrm{~kg} \cdot \mathrm{m}^{-3}[36]\right), \rho_{\mathrm{NaCrO}_{2}}$ the $\mathrm{NaCrO}_{2}$ density $\left(4360 \mathrm{~kg} \cdot \mathrm{m}^{-3}\right.$ [PDF-2/Release $5982012 \mathrm{RDB}$ 04-010-6761), $M_{\mathrm{NaCrO}_{2}}$ and $M_{\mathrm{Cr}}$ the $\mathrm{NaCrO}_{2}$ and $\mathrm{Cr}$ molar masses (107 and $52{\mathrm{~g} . \mathrm{mol}^{-}}^{-}$ 
$\left.599{ }^{1}[36]\right), w_{\mathrm{Cr}}$ the $\mathrm{Cr}$ mass fraction in the stainless steel studied (0.179, Table 1). Finally, the oxide

600 thickness estimated from the mean cavities volume is $0.2 \mu \mathrm{m}$ after $250 \mathrm{~h}$ immersion. As shown in

601 Figs. 5 and 6, the measured oxide thickness is closed to $1 \mu \mathrm{m}$. As a consequence, it can be

602 deduced that the cavities' formation can result from selective oxidation of chromium into sodium

603 chromite. Even if the order of magnitude of the calculated thickness is rough, it can also be said

604 that 1) part of the vacancies created by Cr oxidation or steel dissolution is annihilated at sinks like

605 dislocations leading to the translation of the oxide / metal interface towards the metal bulk and 2)

606 the Kirkendall vacancy flux if it exists is not the main mechanism to explain the cavities

607 formation.

608

609 6. Conclusions

610 The corrosion of an austenitic steel in liquid sodium was investigated in this study. The austenitic

611 steel samples were immersed for 122,250 and $500 \mathrm{~h}$ in liquid sodium with an oxygen content of

$612189 \mu \mathrm{g} \cdot \mathrm{g}^{-1}$ at $650^{\circ} \mathrm{C}$. The steel samples were then characterized by means of complementary

613 techniques, namely scanning electron microscopy, X-ray diffraction, glow discharge optical

614 emission spectroscopy and transmission electron microscopy.

615 The characterizations showed the formation of a $\mathrm{NaCrO}_{2}$ oxide scale at the steel surface together

616 with underlying $\mathrm{M}_{6} \mathrm{C}$ carbide particles rich in molybdenium and iron. The stainless steel substrate

617 and / or the chromite scale were dissolved in parallel with the formation of chromite and carbides.

618 Cavities were observed under the oxide scale within the metal. 
619 The system studied here is composed of liquid sodium containing traces of dissolved oxygen and

620 carbon in contact with a stainless steel. Thermodynamic calculations showed that $\mathrm{NaCrO}_{2}$ and

$621 \mathrm{M}_{6} \mathrm{C}$ are equilibrium phases in such a system.

$622 \mathrm{NaCrO}_{2}$ is formed by the reaction of chromium diffusing from the steel bulk with two

623 components of liquid metal, namely sodium and dissolved oxygen. The $\mathrm{Cr}$ composition profiles

624 exhibited a depleted zone due to the formation of $\mathrm{NaCrO}_{2}$. This is a selective oxidation

625 phenomenon, chiefly external, i.e. it occurs on the stainless steel surface. Mo segregates to the

626 steel surface where it reacts with Fe from the steel and $\mathrm{C}$ dissolved in liquid sodium that diffuses

627 into the steel matrix according to a carburisation phenomenon.

628 Stainless steel and liquid sodium are not in thermodynamic equilibrium. The dissolution of

629 stainless steel occurred since the liquid sodium bath is not saturated in the dissolving species.

630 Thermodynamic calculations, using only the solubilities of $\mathrm{Fe}, \mathrm{Cr}, \mathrm{Ni}, \mathrm{Mn}$ and Mo proposed in

631 the literature for pure metals in liquid sodium, did not explain the large amount of dissolved steel.

632 This means that the solubilities of these elements are higher in sodium containing oxygen than in

633 pure sodium. One explanation could be that some oxides, such as $\mathrm{NaCrO}_{2}$ or $\mathrm{Na}_{4} \mathrm{FeO}_{3}$, are

634 formed in liquid sodium, increasing the driving force of dissolution.

635 As for the cavities, vacancies are created at the steel / $\mathrm{NaCrO}_{2}$ interface by $\mathrm{Cr}$ oxidation,

636 carburization and dissolution of the other elements present in the stainless steel. The vacancies

637 become supersaturated and this leads to the nucleation of the cavities observed. Part of the

638 vacancies created by $\mathrm{Cr}$ oxidation or steel dissolution is annihilated at sinks like dislocations

639 leading to the translation of the oxide / metal interface towards the metal bulk.

640 All of this still needs to be elucidated with additional experimental support 


\section{Acknowledgements}

643 The authors are extremely grateful to Jean-Bernard Guillot for fruitful discussions, to the CEA-

644 Generation 4 / Structural material project for part of the financial support, to V. Lorentz for the 645 exposure of the specimen to liquid sodium made in the Corrona-1 test Bench of the CEA-Saclay.

646

\section{References}

648 [1] R. Dautray, Y. Bréchet, J. Friedel, Les fluides caloporteurs pour neutrons rapides, Académie 649 des sciences, EDPscience, Les Ulis, 2014.

650 [2] J.L. Courouau, F. Balbaud-Célérier, V. Lorentz, T. Dufrenoy, Corrosion by liquid sodium of 651 materials for sodium fast reactors: the CORRONa testing device, in: the proceedings of the 652 International Congress on Advances in Nuclear Power Plants (ICAPP '11), paper 11152, Nice, 653 France, May 2-5, 2011.

654 [3] P. Baqué, L. Champeix, A. Lafon, E. Sermet, Some aspects of corrosion of austenitic steels in 655 flowing sodium, in: Liquid Alkali Metals Proceedings of the International Conference Organized 656 by the British Nuclear Energy Society, Nottingham University, 1973, April 4-6, The British 657 Nuclear Energy Society, London, 1973, pp. 223-231

658 [4] J.R. Weeks, H.S. Isaacs, Corrosion and deposition of steels and nickel-base alloys in liquid 659 sodium, in: Advances in corrosion science and technology, vol. 3, Plenum Press, New York, 660 London, 1973, pp. 1-66. 
661 [5] T. Suzuki, I. Mutoh, T. Yagi, Y. Ikenaga, Sodium corrosion behavior of austenitic alloys and 662 selective dissolution of chromium and nickel, J. Nucl. Mater. 139 (1986) 97-105.

663 [6] T. Gnanasekaran, R.K. Dayal, Liquid metal corrosion in nuclear reactor and accelerator 664 driven systems, in: D. Féron (Ed.), Nuclear Corrosion Science and Engineering, Woodhead 665 Publishing Limited - Cambridge, Philadelphia, 2012, pp.301-328.

666 [7] E. Yoshida, T. Furukawa, Corrosion issues in sodium-cooled fast reactor (SRF) systems, in:

667 D. Féron (Ed.), Nuclear Corrosion Science and Engineering, Woodhead Publishing Limited 668 Cambridge, Philadelphia, 2012, pp.773-806.

669 [8] B.H. Kolster, Mechanism of Fe and Cr transport by liquid sodium un non-isothermal loop 670 system, J. Nucl. Mater. 55 (1975) 155-168.

671 [9] A.W. Thorley, J.A. Bradsley, Structural changes in materials exposed to liquid sodium, J. R. 672 Microsc. Soc. 88 (1968) 431-447.

673 [10] R.M. Singer, A.H. Fleitman, J.R. Weeks, H.S. Isaacs, Measurements of the solubility of iron 674 and chromium in sodium, in: Corrosion by Liquid Metals, Proceedings of the sessions on 675 corrosion by liquid Metals of the 1969 fall meeting of the metallurgical society of AIM, October 676 13-16, 1969, Philadelphia, Pennsylvania, New-York - London: Plenum Press 1970, pp. 561-576. 677 [11] W.P. Stanaway, R. Thompson, Solubility of metals, iron and manganese in sodium, in: 678 Second international Conference on liquid metal technology in energy production - Proceedings 679 part 2, April 20-24, 198, Richland, Washington, J.M. Dahlke 1980, pp. 18.54-18.61.

680 [12] B.H. Kolster, L. Bos, Sodium corrosion in a total molybdenum loop system: construction, 681 experience and results, in: Liquid metal engineering and technology, London: The British 682 Nuclear Energy Society 1984, pp.235-242. 33 
683 [13] I.W. Cavell, M.G. Nicholas, Some observations concerned with the formation of sodium

684 chromite on AISI 316 exposed to oxygenated sodium, J. Nucl. Mater. 95 (1980) 129-144.

685 [14] A.G. Crouch, P.R. Bussey, Corrosion of ferritic steels in flowing sodium, in: Ferritic steels

686 for fast reactor steam generators, The British Nuclear Energy Society, London, 1978, 258-263.

687 [15] A.G. Crouch, The growth and stability of sodium chromite and its influence on corrosion, in:

688 J.M. Dahlke (Ed.), Proceedings of the Second International Conference on Liquid Metal

689 Technology in Energy Production, part 1, April 20-24, 1980, Richland, Washington, 1980, pp. 3-

$690 \quad 43$ to $3-51$.

691 [16] S.H. Shin, J. Lee, J.H. Kim; J.H. Kim, Mechanism of corrosion of 9Cr and 12Cr

692 ferritic/martensitic steels under oxygen-saturated sodium, Corr. Sci. 2016.

693 http://dx.doi.org/10.1016/j.corsci.2016.09.001.

694 [17] P.L.F. Rademakers, B.H. Kolster, Corrosion of various ferritic steels in an isothermal

695 sodium loop system, J. Nucl. Mater. 97 (1981) 309-318.

696 [18] J.L. Courouau, V. Lorentz, M. Tabarant, S. Bosonnet, F. Balbaud-Célérier, Corrosion by

697 oxidation and carburization in liquid sodium at $550^{\circ} \mathrm{C}$ of austenitic steels for sodium fast

698 reactors, in: Proceeding of International Conference on Fast Reactors and related fuel cycles: safe

699 technologies and sustainable scenarios (FR13), 4-7 march 2013, Paris, France.

700 [19] H.U. Borgsted, C.K. Mathews, Applied chemistry of the alkali metals, New-York: Plenum

701 Press, 1987, p.191 and p.184.

702 [20] B.J. Shaiu, P.C.S. Wu, P. Chiotti, Thermodynamic properties of the double oxide of $\mathrm{Na}_{2} \mathrm{O}$

703 with the oxides of $\mathrm{Cr}, \mathrm{Ni}$ and Fe, J. Nucl. Mater. 67 (1977) 13-23. 
704 [21] N.P. Bhat, H.U. Borgstedt, Corrosion behaviour of structural materials in sodium influenced

705 by formation of ternary oxides, Werkstoffe und Korrosion 39 (1988) 115-123.

706 [22] D.R. Fredrickson, M.G. Chasanov, The enthalpy of sodium oxide $\mathrm{Na}_{2} \mathrm{O}$ to $1300 \mathrm{~K}$ by drop 707 calorimetry, J. Chem. Thermodyn. 5 (1973) 485-490.

708 [23] J.D. Noden, A general equation for the solubility of oxygen in liquid sodium, Journal of the 709 British Nuclear Energy 12-1 (1973) 57-62 and 329-331.

710 [24] A. Rist, M.-F. Ancey-Moret, C. Gatellier, P.-V. Riboud, Équilibres thermodynamiques en 711 sidérurgie, Techniques de l’Ingénieur, M 1730 (1974) 1-33 (in French).

712 [25] A.D. Le Claire, The analysis of grain boundary diffusion measurements, Br. J. Appl. Phys. $71314(1963) 351-366$.

714 [26] I. Kaur, Y. Mishin, W. Gust, Fundamentals of grain and interphase boundary diffusion, 715 Wiley, Chichester, 1995.

716 [27] H. Mehrer, Diffusion in solids, in: M. Cardona, P. Fulde, K. von Klitzing, H.-J. Queisser, R.

717 Merlin, H. Störmer (Eds.), Springer series in solid-state sciences, Springer, Berlin, 2007.

718 [28] M. Rivollier, Corrosion des aciers austénitiques par le sodium liquide en présence

719 d'oxygène, PhD Thesis, CentraleSupélec, 2017 (in French).

720 [29] W.P. Stanaway et R. Thompson, « The solubility of transition metals, Mn and Co in liquid 721 sodium », in Material behavior and physical chemistry in liquid metal system, New York -

722 London: Plenum Press, H.U. Borgstedt 1982,.421-427.

723 [30] S.P. Awasthi, H.U. Borgstedt, An assessment of solubility of some transition metals (Fe, Ni, 724 Mn and Cr) in liquid sodium, J. Nucl. Mater. 116 (1983) 103-111. 
725 [31] H.E. Evans, Cavity formation and metallurgical changes induced by growth of oxide scales,

726 J. Mater. Sci. Technol. 4 (1988) 1089-1098.

727 [32] D.J. Young, High Temperature Oxidation and Corrosion of Metals, Elsevier, Amsterdam, 7282008.

729 [33] C. Desgranges, F. Lequien, E. Aublant, M. Nastar, D. Monceau, Depletion and voids

730 formation in the substrate during high temperature oxidation of $\mathrm{Ni}-\mathrm{Cr}$ alloys, Oxid. Met. 79

731 (2013) 93-105.

732 [34] E. Schmucker, C. Petitjean, L. Martinelli, P.-J. Panteix, B. Lagha, M. Vilasi, Oxidation of

733 Ni-Cr alloy at intermediate oxygen pressures. II. Towards the lifetime prediction of alloys, Corr.

734 Sci. 111 (2016) 467-473.

735 [35] M.W. Brumm, H.J. Grabke, Oxidation behaviour of Ni-Al - II. Cavity formation beneath the

736 oxide scale on NiAl of different stoichiometries, Corros. Sci. 34 (1993) 547-561.

737 [36] David R. Lide, CRC Handbook of Chemistry and Physics, CRC Press Inc, 2009, 90th ed., 7382804 p., (ISBN 978-1-420-09084-0).

739

$740 \quad$ Legends

741 Table 1. Composition in wt.\% of the 316L(N) stainless steel tested.

742 Figure 1. 316L(N) steel microstructure after electrochemical etching (oxalic acid, 10 vol.\%, 0.5 $743 \quad$ A.cm $\left.{ }^{-2}\right)$.

744 Figure 2. Mass gain or loss of samples immersed at $650^{\circ} \mathrm{C}$ in liquid sodium containing an 745 oxygen content of $189 \mu \mathrm{g} \cdot \mathrm{g}^{-1}$ as a function of time. 
746 Figure 3. Sample immersed for $250 \mathrm{~h}$ at $650^{\circ} \mathrm{C}$ in liquid sodium containing an oxygen content of $747189 \mu \mathrm{g} \cdot \mathrm{g}^{-1}$, a) SEM observation in secondary electrons at $2 \mathrm{kV}$ and associated b) and c) EDS 748 spectra); The steel surface is covered with a layer of triangle-shaped crystals rich in $\mathrm{Na}, \mathrm{Cr}$ and 749 O. Mo and Fe rich particles are also detected.

750 Figure 4. XRD diagram, specimen immersed for $500 \mathrm{~h}$ at $650^{\circ} \mathrm{C}$ in liquid sodium containing $751189 \mu \mathrm{g} \cdot \mathrm{g}^{-1}$ oxygen. $\mathrm{NaCrO}_{2}$ and $\mathrm{Fe}_{3} \mathrm{Mo}_{3} \mathrm{C}$ are identified together with the austenite substrate.

752 Figure 5. SEM cross-section observations (backscattered electrons); sample immersed for $250 \mathrm{~h}$ 753 at $650^{\circ} \mathrm{C}$ in liquid sodium with a $189 \mu \mathrm{g} \cdot \mathrm{g}^{-1}$ oxygen content.

754 Figure 6. GDOES chemical depth profiles obtained for a sample immersed in liquid sodium for $755250 \mathrm{~h}$ at $650^{\circ} \mathrm{C}$ with an oxygen content of $189 \mu \mathrm{g} \cdot \mathrm{g}^{-1}$.

756 Figure 7. Cross section of a sample immersed for $250 \mathrm{~h}$ at $650^{\circ} \mathrm{C}$ in liquid sodium with $189 \mu \mathrm{g} \cdot \mathrm{g}^{-}$

$757{ }^{1}$ of oxygen (HAADF image). The $\mathrm{NaCrO}_{2}$ scale is visible at the top of the image in black.

758 Figure 8. Chromium composition profile obtained by EDX analysis at the locations shown by 759 arrows 1 and 2 in Fig. 7. Abscissa 0 corresponds to the location of the grain boundary where a 760 chromium depletion is observed.

761 Figure 9. Chromium composition profile obtained by GDOES analysis for samples immersed 762 during 122,250 and $500 \mathrm{~h}$ at $650^{\circ} \mathrm{C}$ in liquid sodium containing $189 \mu \mathrm{g} \cdot \mathrm{g}^{-1}$ of oxygen.

763 Figure 10. Oxides' stability: a) Ellingham diagram of $\mathrm{NaCrO}_{2}, \mathrm{Na}_{4} \mathrm{FeO}_{3}$ and $\mathrm{Na}_{2} \mathrm{O}$ plotted 764 together with the chemical potential of oxygen for different oxygen contents in liquid sodium; b) 765 Gibbs free energy diagram for the equilibrium between $\mathrm{Na}-\mathrm{O}$ liquid phase and $\mathrm{Na}_{2} \mathrm{O}$. 
766 Figure 11. Carbides'stability: a) mole fraction of stable phases, b) Composition of $\mathrm{M}_{6} \mathrm{C}$ carbide

767 as a function of temperature and c) Composition of $\mathrm{M}_{23} \mathrm{C}_{6}$ carbide as a function of temperature.

768 
$1 \quad$ Table 1.

\begin{tabular}{lllllllllllll}
\hline $\mathrm{Fe}$ & $\mathrm{Cr}$ & $\mathrm{Ni}$ & $\mathrm{Mo}$ & $\mathrm{Mn}$ & $\mathrm{C}$ & $\mathrm{Si}$ & $\mathrm{P}$ & $\mathrm{S}$ & $\mathrm{Ti}$ & $\mathrm{Al}$ & $\mathrm{Cu}$ & $\mathrm{Co}$ \\
\hline Balanced & 17.9 & 12.1 & 2.35 & 1.72 & 0.012 & 0.45 & 0.034 & 0.025 & 0.0015 & 0.0025 & 0.0025 & 0.0008 \\
\hline
\end{tabular}

2 


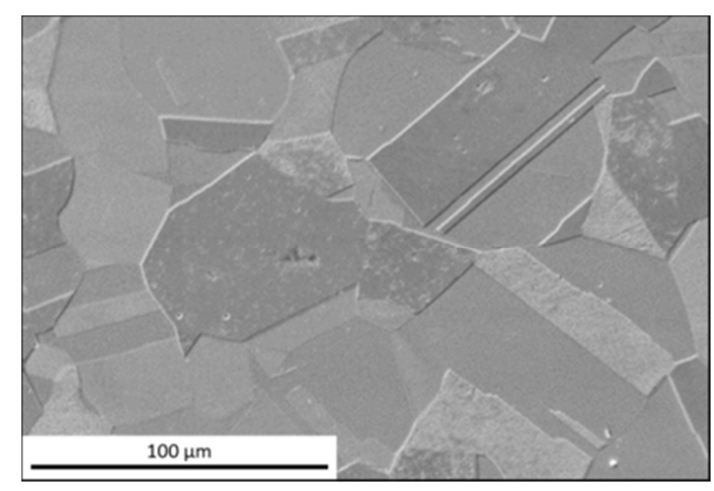




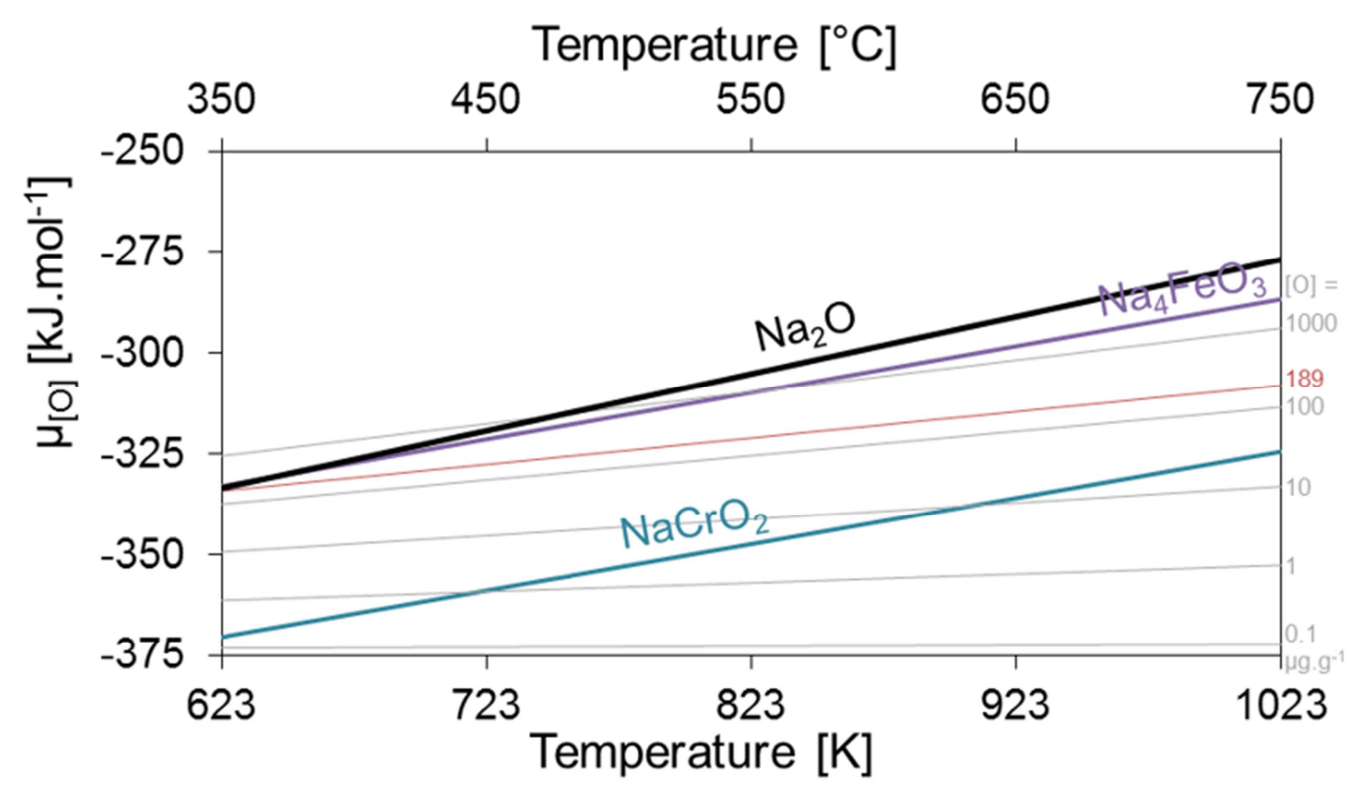

Fig.10a

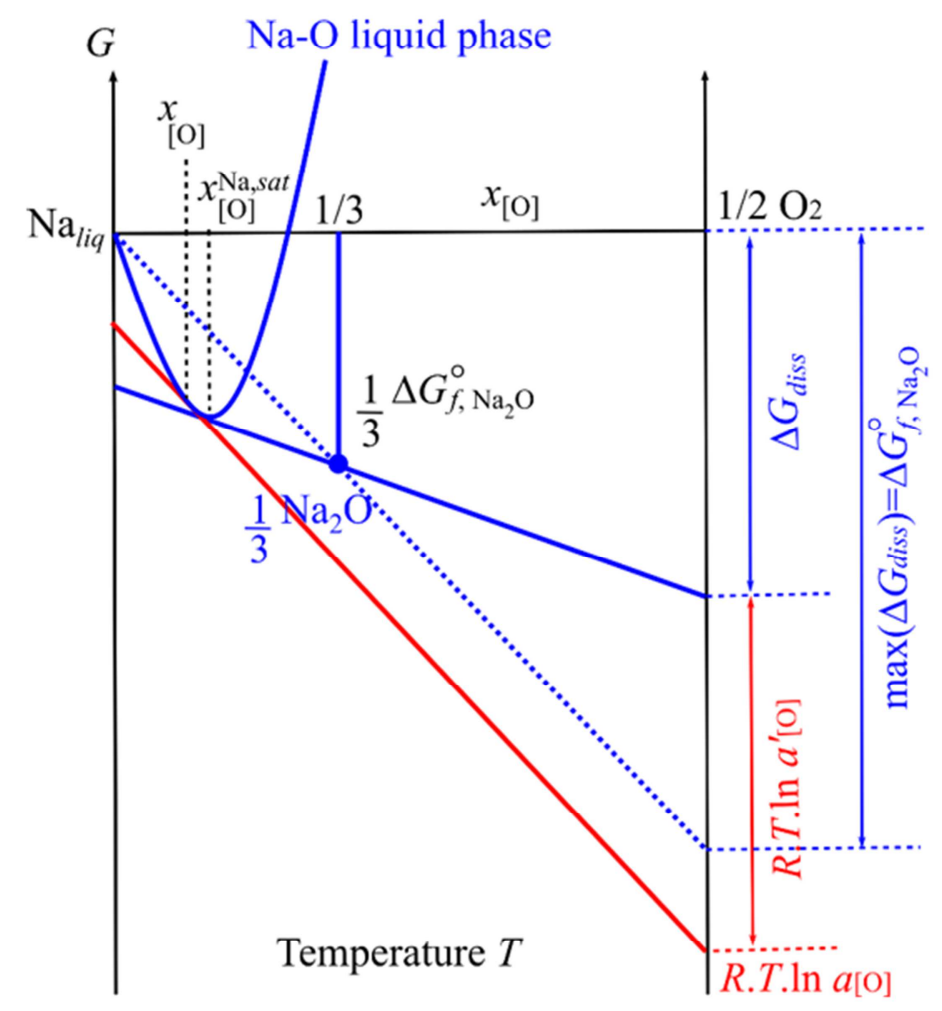

Fig.10b 


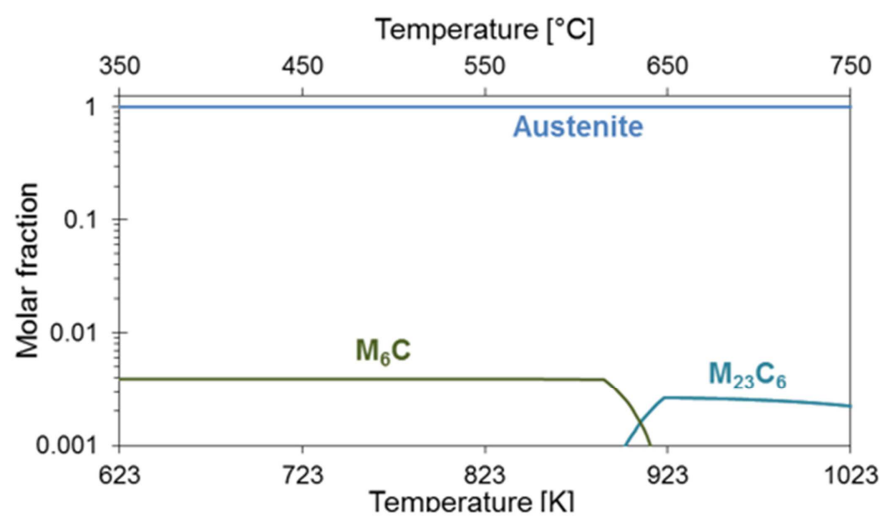

Fig. 11a

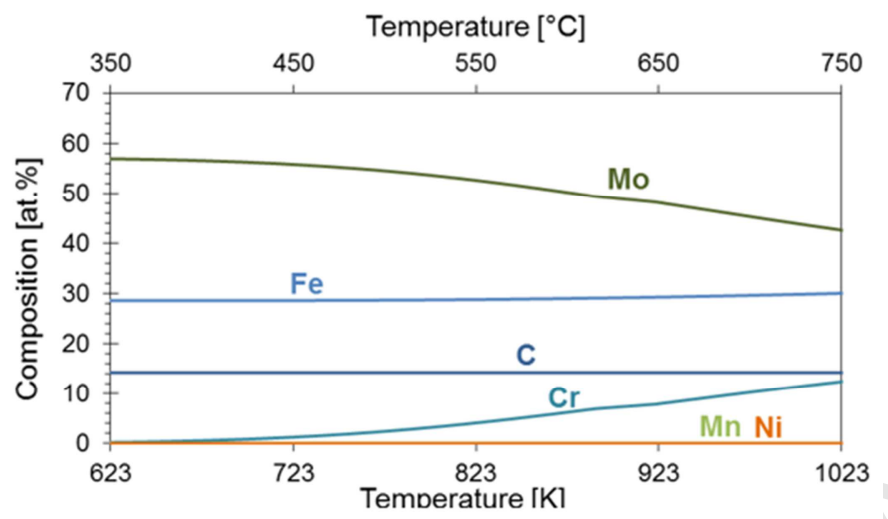

Fig. $11 b-M_{\underline{6}} \underline{C}$

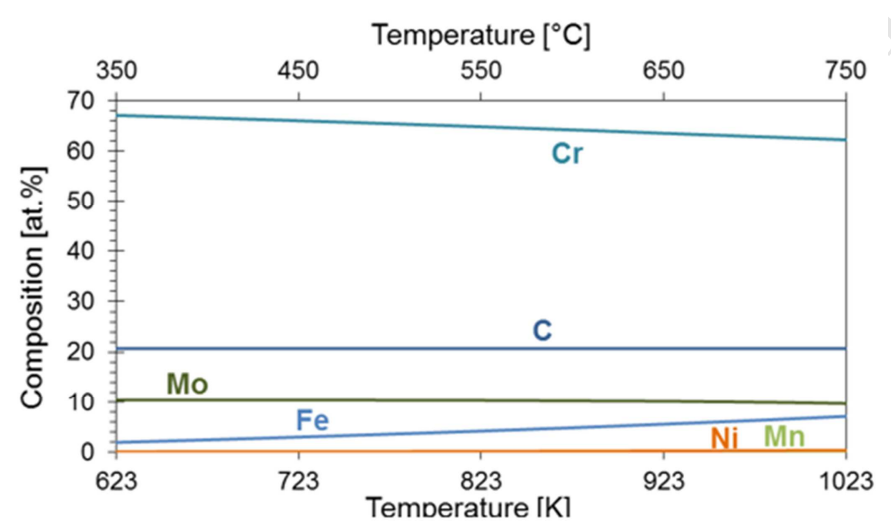

Fig. $11 \mathrm{c}-\mathrm{M}_{\underline{23}} \underline{\mathrm{C}}_{6}$ 


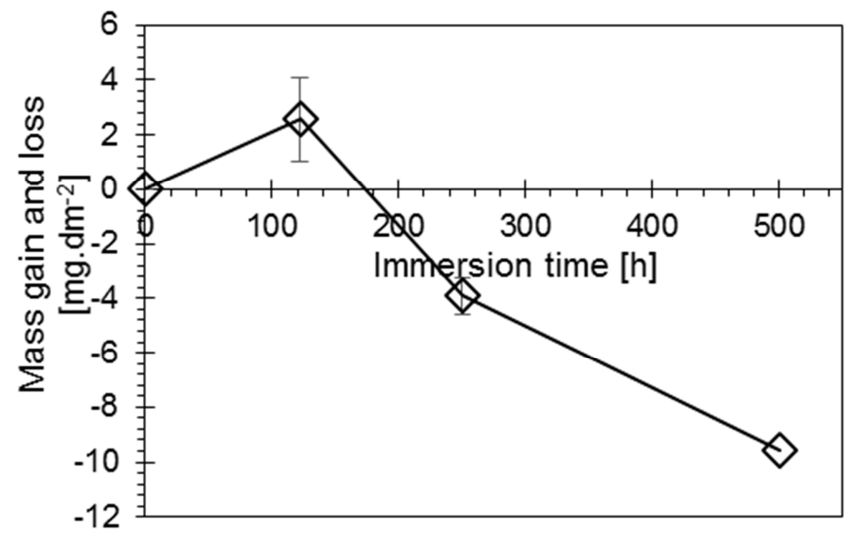



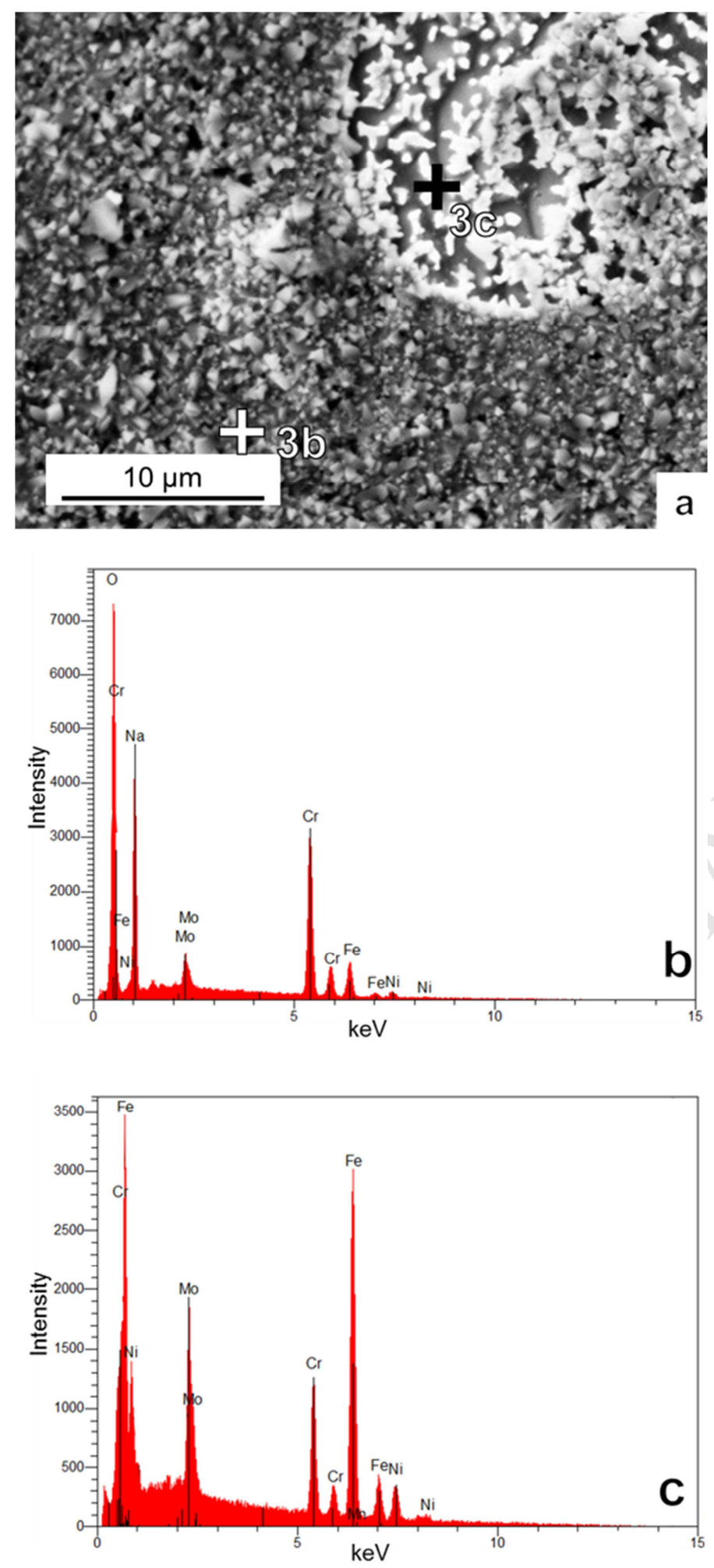


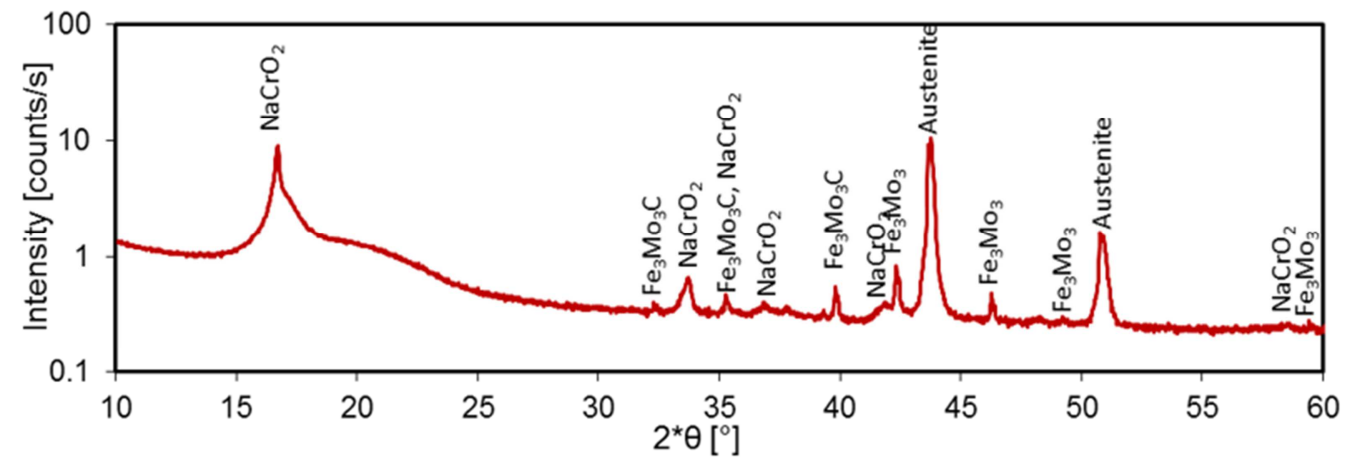




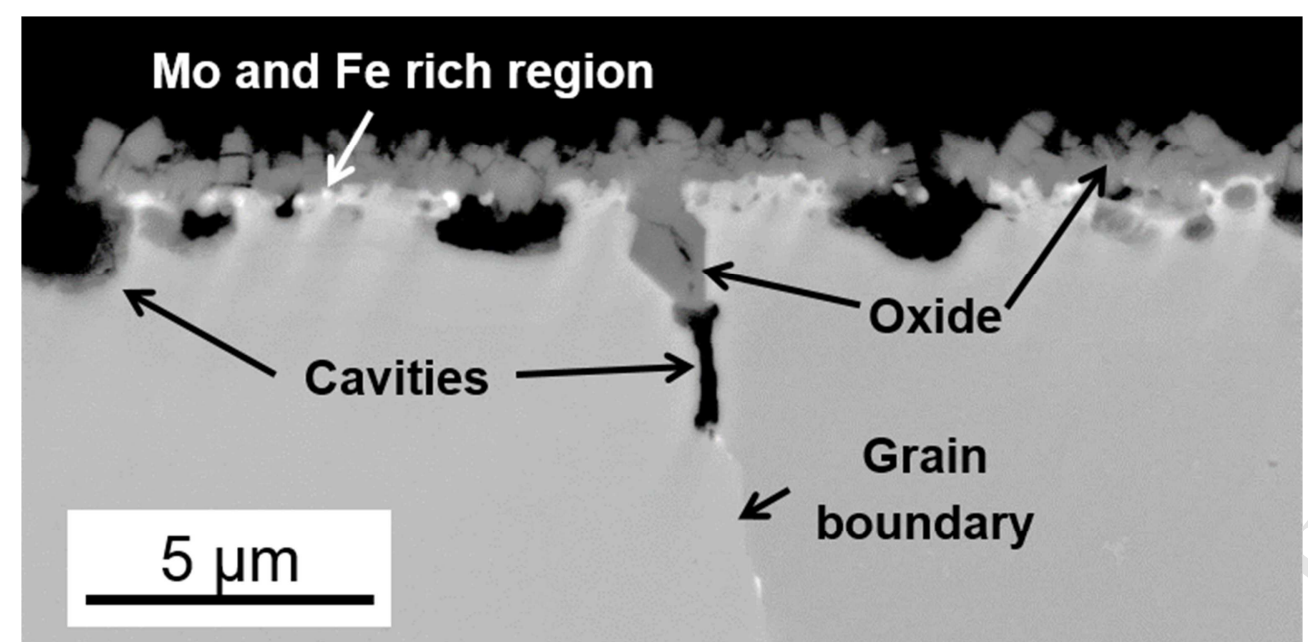




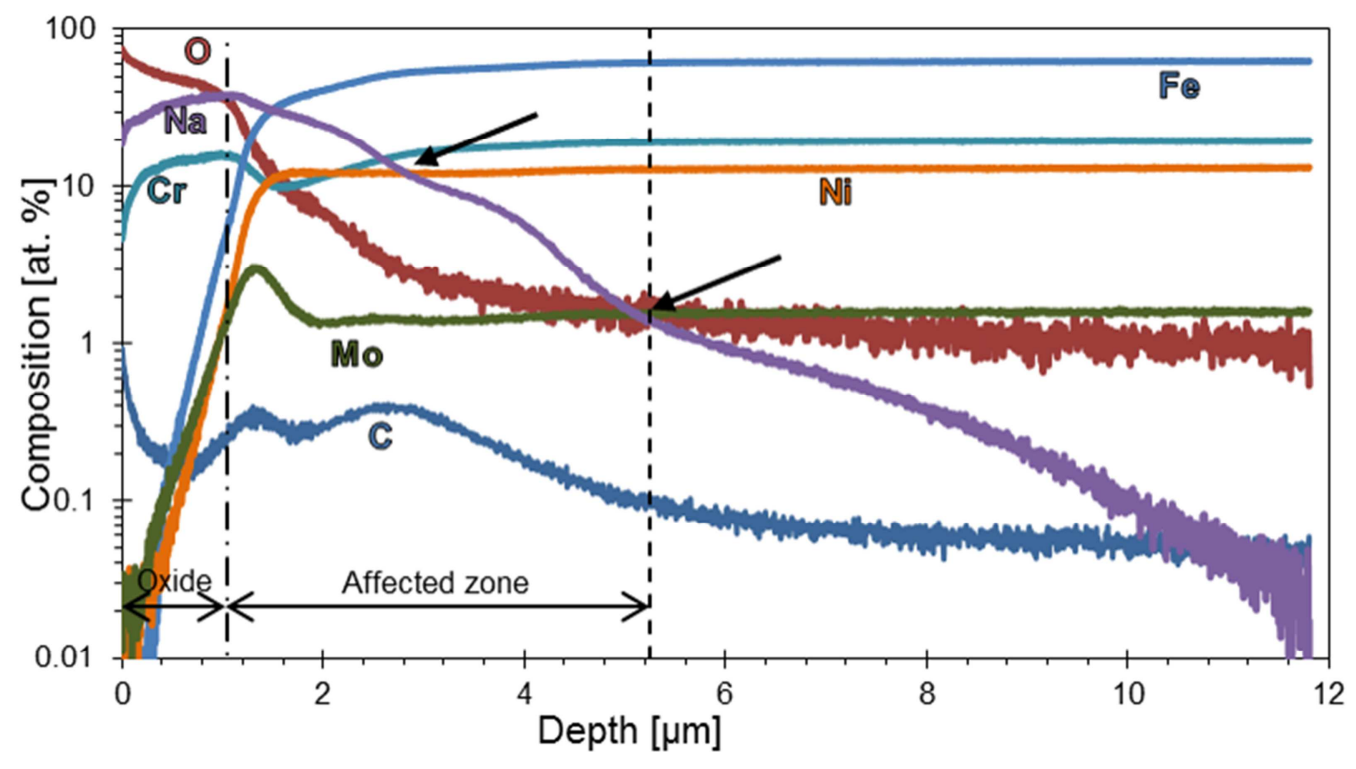




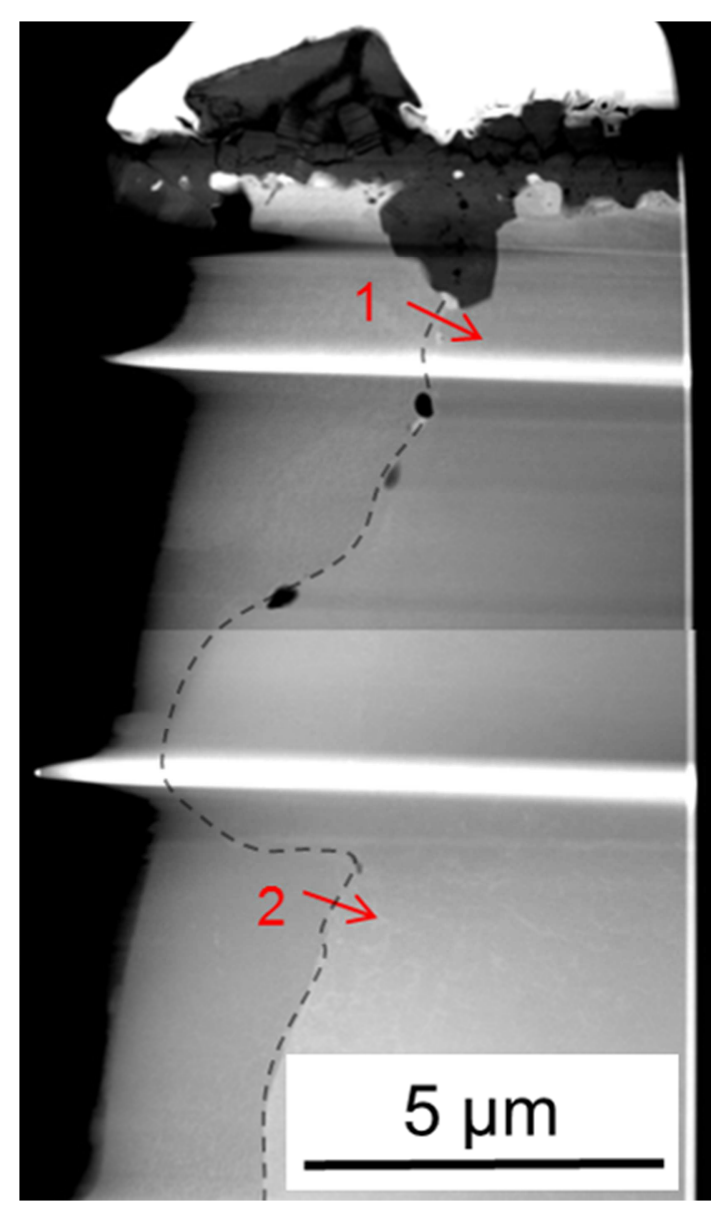




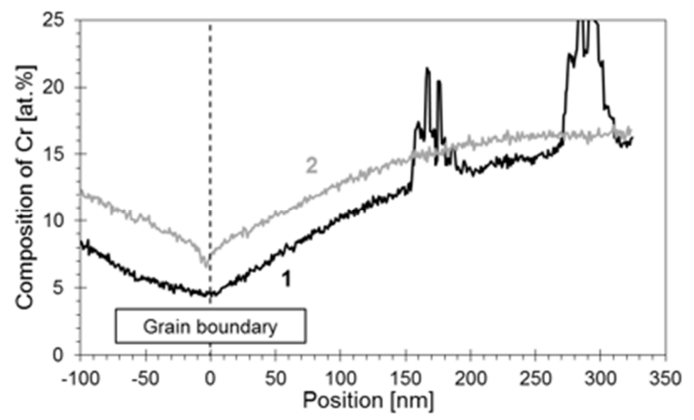




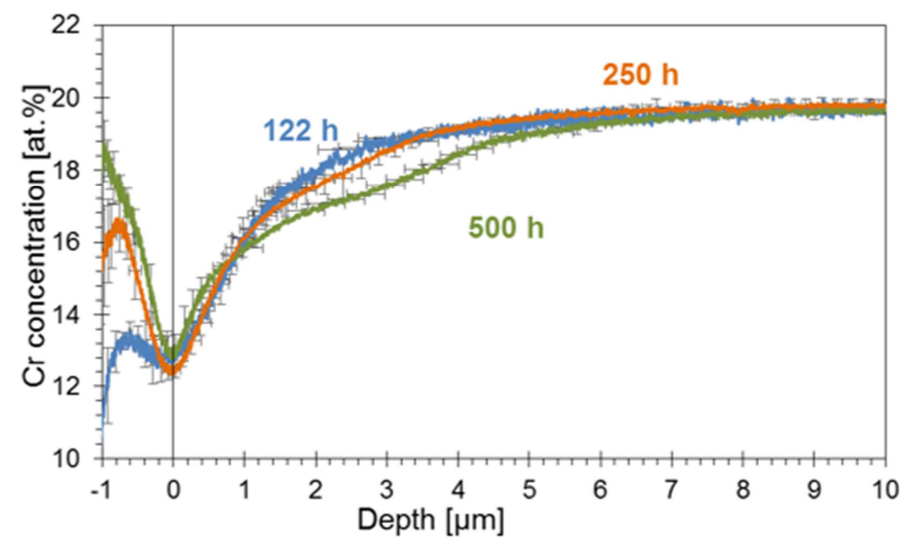


- Austenitic steel is immersed in liquid sodium containing oxygen at $650^{\circ} \mathrm{C}$ until $500 \mathrm{~h}$

- $\mathrm{NaCrO}_{2}$ is formed. $\mathrm{O}$ and $\mathrm{Na}$ come from liquid metal, $\mathrm{Cr}$ from steel

- Mo and Fe rich $\mathrm{M}_{6} \mathrm{C}$ carbides are formed. Mo and Fe come from steel, $\mathrm{C}$ from liquid metal

- Cavities are also observed. They are due to oxidation, carburization and dissolution

- Cr depletion is observed nearby the surface and in the vicinity of grain boundaries 